Notre Dame Law School

NDLScholarship

Journal Articles

Publications

1987

\title{
Practical Principles, Moral Truth, and Ultimate Ends
}

John M. Finnis

Notre Dame Law School, john.m.finnis.1@nd.edu

Germain Grisez

Joseph Boyle

Follow this and additional works at: https://scholarship.law.nd.edu/law_faculty_scholarship

Part of the Legal History Commons, and the Natural Law Commons

\section{Recommended Citation}

John M. Finnis, Germain Grisez \& Joseph Boyle, Practical Principles, Moral Truth, and Ultimate Ends, 32 Am. J. Juris. 99 (1987).

Available at: https://scholarship.law.nd.edu/law_faculty_scholarship/846

This Article is brought to you for free and open access by the Publications at NDLScholarship. It has been accepted for inclusion in Journal Articles by an authorized administrator of NDLScholarship. For more information, please contact lawdr@nd.edu. 


\title{
PRACTICAL PRINCIPLES, MORAL TRUTH, AND ULTIMATE ENDS
}

\author{
Germain Grisez, Joseph Boyle, and John Finnis
}

\begin{abstract}
The natural-law theory on which we have been working during the past twenty-five years has stimulated many critical responses. We have restated the theory in various works, not always calling attention to developments. This paper reformulates some parts of the theory, taking into account the criticisms of which we are aware. We append an annotated, select bibliography.
\end{abstract}

\section{INTRODUCTION}

\section{A. Please Note Well}

WHILE THIS PAPER PROPOSES PHILOSOPHICAL clarifications and arguments rather than textual interpretations, it uses some language common in the (broadly speaking, Thomistic) natural-law tradition from which we developed the theory. But what we say here differs in various ways from the theories articulated by Aristotle, Thomas Aquinas, and others.

In previous works covering more or less the same ground as this paper, we have expressed key concepts in various ways. Here, again, we use language in ways not in all cases the same as in our other works or in the tradition. But we try to be consistent throughout the present paper in using certain key terms which we put in small capitals in their first occurrences.

For simplicity, in this paper we generally use only the singular in speaking of actions, purposes, goods, and so on. For example, though an action often has more than one purpose, we usually talk about "the purpose" as if each action had but one. Likewise, one often chooses to do something with the hope of achieving diverse benefits for oneself and/or another (or others), but we usually talk about "the intended benefit" or "the good in which one is interested" as if an agent intended only a single benefit for a single person-himself or herself.

Similarly, very many actions are done (and some important ones can only be done) by groups of people. But, for simplicity, we almost always talk about "the acting person" or "the agent," as if all agents were individuals acting alone.

There is no adequate way in English to refer to the motivation, consequent upon sensory cognition, generically common to human beings and brute animals. Motivations of this sort normally are effective 
without one's being aware of them. So "feeling" and "emotion" have unwelcome connotations of conscious experience and intensity, but, for want of better words, we use these, and use them interchangeably.

The present paper reformulates only some parts of the theory of practical and moral knowledge on which we have been working. For example, we do not deal here with the distinction between an act's object and side effects. And we deal only incidentally with the important, intermediate moral principles which we call "modes of responsibility." Moreover, we treat no specific normative issue here, and articulate some practical and moral knowledge only as necessary for our theoretical purpose.

We deal here, mainly, with the following matters: the first principles of practical knowledge and of morality, their relationship to other cognition, their specific truth, their relationship to the ultimate ends of human persons (taking "end" in several different senses), and their relationship to religion.

As a theory of some of the principles of human action, what we offer here presupposes many theses of metaphysics and philosophical anthropology - for example, that human intelligence is irreducible to material realities, that doing and making are irreducible to one another, that human persons and their actions are caused by an uncaused cause, and so on. We defend many such presuppositions elsewhere.

\section{B. Framework for the Analysis: Free Choice}

Perhaps the most important presupposition from philosophical anthropology is that human persons can make free choices. Whether they assented to this proposition or not, most who have contributed to ethical theory, whether in ancient or more recent times, have denied, overlooked, or, at best, not fully appreciated the role of free choice in morality. Because of the importance of free choice, we have tried hard in other works to explain and defend the proposition that human persons can make free choices.

Since we hold that free choice is central (and choice presupposes both intellectual cognition and prior willing of goods), we frequently and sharply distinguish intelligible factors from factors contributed by sense and imagination, and volitions, including choices, from feelings. To those not accustomed to making these distinctions, our making them as sharply as we do may give the impression that we hold a dualistic view of human personality and action. But we do not. All the distinctions are made, for analytic purposes, among the dynamic aspects of one reality, the acting person, who alone is properly said to imagine, understand, feel, and will. 
For some, the fundamental problem of ethical theory is how to escape egoism. They will wonder why we say so little about it. Our reason: The debate between egoism and its alternatives belongs to normative ethics-as one issue among many-not to the foundations of ethics. One can choose freely whether to be an egoist. But one has no choice whether harmony among persons is good, or whether harmony is fostered or blocked by egoism: And, in general, the practical principles which make choices possible-and which are not themselves chosen, egoistically or otherwise-must be presupposed in any inquiry about the merits of egoism. [We deal with egoism more fully in section V(A).]

Similarly, some wonder whether the theory we defend is teleological or deontological. The answer: Neither. Unlike teleological theories, this one shows why there are absolute moral norms. (We deal with this matter sufficiently in other works.) Moreover, unlike teleological and like deontological theories, the position we defend is that morally good free choices are intrinsic to the supreme good of human persons. But to assume that this theory must therefore be deontological is a mistake.

Deontological theories treat practical reason or will as a selfconstituting source of morality. Excluding determination by naturally given desires as alien to morality, some theories of this sort-Kant's is the most famous - try to derive moral norms from freedom itself and its necessary conditions. On such an account, the fulfillment of natural human desires has no.place in the definition of morally good will. Other theories considered deontological try to ground morality in God's free will, on the assumption that, being supreme, its only norm is itself. For such theories, rightness is determined by arbitrary divine law, not by divine wisdom directing humankind to its fulfillment.

Against deontological theories, we hold that moral truths direct free choices toward actions which tend to satisfy natural desires. Such actions help to fulfill persons as individuals and in communion. Against teleological theories, however, we hold that some of these desires are for fulfillments not only realized but constituted by morally good choices, including mutual commitments.

The centrality of free choice in moral theory explains not only why our account of practical and moral principles diverges from some contemporary views, but also why it departs in some respects from classical models to which it is in other respects indebted. As we show in this paper, the reality of free choice is incompatible with the supposition-for instance, of Aristotle-that there is a single natural end of human life [sections IV(B); X; XI(A).]

The theory we defned also departs from classical models-at least, as many have understood them-by taking full account of the fact 
that the moral ought cannot be derived from the is of theoretical truthfor example, of metaphysics and/or philosophical anthropology. Logically, of course, one can derive a moral ought from an is, whenever the is expresses a truth about a reality which embodies a moral norm. Thus, from "This is the act an honest person would do" one can deduce "This act ought to be done." But from a set of theoretical premises, one cannot logically derive any practical truth, since sound reasoning does not introduce what is not in the premises. And the relationship of principles to conclusions is a logical one among propositions. Therefore, the ultimate principles of morality cannot be theoretical truths of metaphysics and/or philosophical anthropology.

That this is not simply a logician's pedantry will be made clear by our account of practical truth and moral truth [sections IV(A-B); VII(D); $\operatorname{VIII(A-C).]~}$

\section{Part One: Practical Principles}

\section{The Motives of Specifically Human Acts}

\section{A. Púrposes of Rationally Guided actions}

Principles are uncovered by examining that of which they are the principles. The principles we are concerned with here are motives of human action. As principles, they will be basic motives, irreducible to any prior motives of the same sort.

Some things people do-instinctive behavior and intelligently planned performances whose only ultimate motives are feelings-are not specifically human in their motivation. For example, a three-year old child cleverly raids the cookie jar, or a traveler, spontaneously responding to nature's call, follows signs to a restroom. In some of our works, such behavior was said to be done by "spontaneous willing." It was a mistake to say "willing," for reasons which will become clear in section $\mathrm{II}(\mathrm{C})$. We here set aside such behavior, not specifically human in its motivation.

The actions we are concerned with in this paper are those initiated by free choice. Such actions are done for the sake of something; they are rationally guided (whether or not they are morally good and entirely reasonable in other respects). The first type of principle we treat is that for the sake of which such an action is done.

That for the sake of which one acts is one's PURPOSE in acting; one hopes that this purpose will be realized through and/or in one's action. A purpose in this sense is a state of affairs-something concrete which can exist or not exist in reality. For example, if one enters a 
contest, one's purpose is to win a prize; if one does not feel well and goes to the doctor, one's purpose is to get better.

People do not always have a purpose distinct from their action; sometimes doing the action is itself their purpose in acting. That is very often the case when one plays a game or reads a novel.

\section{B. Basic Goods as Reasons Underlying Purposes}

We distinguish between purposes and that about a purpose which makes one rationally interested in acting for it. We call the latter a GOOD. For example, among goods are winning and being healthy, considered insofar as they can be realized-protected, promoted, and so on-not only by one action but by many possible actions. In entering a contest or going to the doctor, one's purpose of winning or regaining health only PARTICIPATES in the goods of winning and health, in which one is interested more generally.

To explicate this participation relationship between a purpose and a good, we say: Achieving the purpose will INSTANTIATE the good which is the reason one is interested in acting for that purpose.

Even when one's purpose is not distinct from one's action, something about the action underlies one's rational interest in doing it. One's reasons for playing a particular game or reading a particular novel are goods which are only instantiated through actions chosen for these reasons. Thus, playing and knowing always have their basic appeal, insofar as they are goods, but like other goods they can be realized only in limited ways through particular actions.

Some goods are reasons for acting which need a further reason to explain the interest people take in them. We call such reasons for acting INSTRUMENTAL GOODS. For example, as a reason for acting, winning a prize needs a further reason which motivates one to win. The further reason will be the reason why one is interested in some further purpose, such as using the prize, showing that one has the necessary capabilities, and so on.

One does finish deliberating and begin acting, and there cannot be an infinite regress in the goods which are reasons for acting. Plainly, then, there are reaons for acting which need no further reason; these are goods, one or more of which underlie any purpose. We call these BASIC GOODS. Actions specifically human in their motivation are done for the sake of one or more of these goods; every such action is chosen in view of one or more BASIC PURPOSES. Basic purposes are those whose achievement will immediately instantiate basic goods. 


\section{Benefit and Goal: Distinct Aspects of a Purpose}

This paper concerns rationally motivated actions. But people never do such actions without emotional motives as well [see section VII(B)]. Feelings bear not on the intelligible good as such but on the action's concrete purpose or on something linked by psychological association with that purpose. One perhaps has experienced and remembers a more or less similar state of affairs; in any case, one can more or less clearly imagine the purpose or something related to it. Something about it, as thus imagined, inclines one to do the action.

Because there are both rational and emotional motives, which bear upon the purpose of an action in different ways, one can distinguish between two aspects of a purpose. In one aspect a purpose is desired by reason of an intelligible good; in another aspect a purpose is desired as concrete and imaginable.

Insofar and only insofar as it is concrete and imaginable, a purpose is emotionally desired. As an object of feeling, a purpose is a particular objective. We call such an objective a GOAL. So a purpose is a goal insofar as envisaging the purpose arouses the feelings an agent needs to act for it.

Insofar as the purpose of one's action is proposed not by imagination but by intellectual knowledge, it is volmtionally desired. The purpose remains a concrete state of affairs. But when one deliberates about acting for it, propositional knowledge commends doing so by reason of an intelligible good, ultimately by reason of a basic good. If one chooses to act for the purpose, one hopes to share in the good and be more or less fulfilled (or to help another to share in it and be fulfilled). We use ANTICIPATE to signify the relationship between practical knowledge directing a rationally guided and chosen action toward fulfillment and the fulfillment for which one hopes.

We use BENEFIT to signify the intelligible aspect of a basic purpose. Like a goal, a benefit is particular, but unlike a goal as such, a benefit directly contributes to someone's fulfillment. And so, one who chooses to act for a purpose not only desires and expects to reach a certain goal but anticipates and hopes to realize and enjoy (or help another to realize and enjoy) some benefit through the action. Where the purpose is not basic but instrumental to some further purpose, it too has an intelligible aspect which may be called an EMPOWERMENT.

Since rationally guided and chosen actions always are done with emotional motivation as well, the purpose of every such action includes a goal. Rational motives motivate toward some fulfillment of the person as a whole; emotional motives motivate toward some fulfillment 
of the person's sentient part. But, although they are distinct from one another, emotional and rational motives are dynamically united.

Indeed, agents, by understanding and generalizing goals, can think of them as reasons for acting - that is, as intelligible goods. But they are only instrumental ones, since a fulfillment of sentient nature just as such is not yet a fulfillment of the person as a whole. Thus, eating a particular meal is a goal, and one understands eating in general as a good, in which one is interested. But eating can only be deliberately chosen insofar as it is instrumental to basic goods, such as life and fellowship. Or, to take the earlier example; winning is the goal of entering a particular contest; this goal generalized is the intelligible good of winning, for people who enter contests have a general interest in this sort of empowerment. The good of winning is an intelligible good, but not a basic one. Those interested in winning always are more interested in the benefits (in terms of one or more of the basic goods) which they hope to achieve from winning.

Even without the anticipation of any benefit or empowerment, feelings can incite behavior toward a goal. Understanding that goal-not as a reason for acting but as something to be brought about-an agent can pursue it by an intelligent causal process. A technical "means" (such as a tool, a manipulative process, a sign) is used to reach the "end." Such behavior often occurs even in small children. Being intelligently guided, it is easily confused with rationally motivated action. What is said in some of our works about "spontaneous willing" involves precisely that confusion.

\section{First Principles of Practical Reasoning and Wrlling}

In all rationally motivated actions, there is a guiding judgment and a choice. The judgment proposes and shapes the action as what is to be done or ought to be done. The choice is the will to do that action rather than not and rather than any. other. This distinction in actions is rooted in a distinction in their principles. Thus, one can distinguish between the intellectual knowledge of the basic goods as reasons for choosing and the corresponding volition toward the goods.

The knowing which directly shapes action is neither mere insight nor a process of reasoning but a judging which proposes: This action is to be done or ought to be done. Such a judgment is reached by reasoning from one or more basic goods. The simplest case of such reasoning is: This is to be done because it probably will realize a certain benefitthat is, instantiate such and such a basic good. This reasoning process assumes: Such and such a good is to be realized (protected, promoted, 
and so on). Thus, one way the basic goods function as principles of actions is through being known as ultimate rational grounds (principles of practical reasoning) for proposing actions to be done for certain benefits (anticipated instantiations of those goods).

Correspondingly, the choice to do an action presupposes a volition toward the intelligible aspect of the purpose. This volition, in turn, presupposes a fundamental volition toward the relevant basic good. This fundamental volition corresponds to the principles of practical knowledge, which provide its object. Thus, the other way the basic goods function as principles of action is by being willed as the first objects of volition.

We use CHOICE to signify a volition bearing on an action to be done. We use INTEREST to signify a volition bearing on the intelligible aspect (whether benefit or empowerment) or some set of potential (or both potential and actual) purposes. We use INTENTION to signify a volition bearing on the intelligible aspect (whether benefit or empowerment) of a purpose for which an act actually is chosen. To signify the type of volition (presupposed by interest and intention) which bears on the basic goods, we speak of ALIVENESS to those goods or SIMPLE VOLITION of them-'"simple" because basic and uncomplicated. Thus, specified by the first principles of practical knowledge, aliveness to the basic goods underlies one's various interests which, in turn, take specific form in the intentions with which one chooses to act for purposes.

The question naturally arises: If the principles of practical knowledge serve as ultimate rational grounds for proposing actions to be done, how can these principles themselves come to be known? As first principles, they cannot be derived from any theoretical knowledge [sections I(B); IV(A); VI(B); VIII(C)]. Thus, they cannot be verified by experience or deduced from any more basic truths through a middle term. They are self-evident.

Self-evident principles are per se nota-known just by knowing the meaning of their terms. This does not mean that they are mere linguistic clarifications, nor that they are intuitions-insights unrelated to data [see section III(B)]. Rather, it means that these truths are known (nota) without any middle term (per se), by understanding what is signified by their terms.

\section{Practical Principles and Their Genesis}

\section{A. Which ARe the Basic Goods}

The most direct way to uncover the basic goods is by considering actions and asking, "Why are you doing that?" and "Why should 
we do that?" and so on. Persisting with such questions eventually uncovers a small number of basic purposes of diverse kinds. These purposes arouse interest because their intelligible aspects are instantiations of the diverse basic goods.

The diversity of the basic goods is neither a mere contingent fact about human psychology nor an accident of history [section IV(B-C)]. Rather, being aspects of the fulfillment of persons, these goods correspond to the inherent complexities of human nature, as it is manifested both in individuals and in various forms of community.

In other works we have provided somewhat different lists of the most general categories of basic goods. But the following seven categories now seem to us adequate.

(1) As animate, human persons are organic substances. Life itself-its maintenance and transmission-health, and safety are one category of basic good.

(2) As rational, human persons can know reality and appreciate beauty and whatever intensely engages their capacities to know and to feel. Knowledge and esthetic experience are another category of basic good.

(3) As simultaneously rational and animal, human persons can transform the natural world by using realities, beginning with their own bodily selves, to express meanings and serve purposes. Such meaning-giving and value-creation can be realized in diverse degrees. Their realization for its own sake is another category of basic good: some degree of excellence in work and play.

The preceding categories of goods we call substantive. Although the substantive goods provide reasons for acting, their instantiations, even when caused by chosen actions, do not involve choices. Everyone shares in substantive goods even before deliberately pursuing them. They are first received as gifts of nature and parts of a cultural heritage. But children quickly come to see these substantive goods as fields in which they can care for, expand, and improve upon what they have received. Life, knowledge, and skilled performances are basic goods and principles of practical knowledge just insofar as they can be understood and, being understood, can be cherished, enhanced, and handed on to others.

Another dimension of human persons is that they are agents through deliberation and choice, who can strive to avoid or overcome various forms of personal and interpersonal conflict-or, to put the matter positively, who can strive to foster various forms of harmony. So, among the basic goods are certain forms of harmony. The instantiations of these goods include the choices by which one acts for them. So we call them REFLEXIVE goods. 
For reasons which will become clear later [section XI(A-B)], not all instantiations of reflexive goods are morally good, although true and lasting fulfillment in them must be so.

(4) Most obvious among the reflexive goods are various forms of harmony between and among individuals and groups of persons-living at peace with others, neighborliness, friendship.

(5) Within individuals and their personal lives, similar goods can be realized. For feelings can conflict among themselves and also can be at odds with one's judgments and choices. The harmony opposed to such inner disturbance is inner peace.

(6) Moreover, one's choices can conflict with one's judgments and one's behavior can fail to express one's inner self. The corresponding good is harmony among one's judgments, choices, and performancespeace of conscience and consistency between one's self and its expression.

(7) Finally, most people experience tension with the wider reaches of reality. Attempts to gain or improve harmony with some more-thanhuman source of meaning and value take many forms, depending on people's world views. Thus, another category of reflexive good is peace with God, or the gods, or some nontheistic but more-than-human source of meaning and value.

Although actions through which one more or less directly participates in a basic good can be chosen by reason of that basic good, they also can be chosen for a purpose whose intelligible aspect is a benefit (or even an empowerment) which instantiates some other good. For example, although one can choose to play a game simply for play's sake, one can play for fellowship, to make money, and so on.

\section{B. Genesis of the First Practical Principles}

As we said [section II(D)], the first practical principles, although self-evident, are not intuitions-insights without data. What data are available?

Human persons have natural dispositions toward what will fulfill their potentialities. Some of these dispositions are natural appetitesthat is, dispositions of a person's various parts and powers toward their own actualizations. Others are sensory appetites (including aversions)-that is, emotional responses. Both types of dispositions sometimes motivate behavior more elemental than intelligently guided actions, and one thus becomes aware of them. These natural dispositions, insofar as they are experienced, provide data for the insights in which one knows the first, self-evident principles of practical knowledge corresponding to the substantive goods. 
Although the insights whose content is the self-evident principles of practical knowledge have for data one's natural inclinations, one's understanding of the substantive goods does not remain forever aslimited as it is at first.

Knowing that health is a good to be preserved by appropriate actions, people study what health is. So, one acting to serve this interest today has the advantage of much theoretical study and a heritage of experience unavailable to early people.

Similarly, scientists who systematically. pursue truth proceed from the same first practical principle as they did when as curious children they first chose to seek an answer to some question. But now they not only know better how to pursue truth, but have a deeper insight into the truth to be known, and can appreciate, in a way children cannot, how knowing is an aspect of integral human fulfillment.

In one's grasp of the practical principles directing toward reflexive goods, the data include volitions. Various forms of disharmony involving choices bearing upon substantive goods thwart one's interests. The will's frustrated intentions are natural inclinations which are data. And so, volitions specified by the substantive goods are part of the data for the insights whose content is the reflexive practical principles.

The volitions included in the data for understanding reflexive practical principles should not be confused with the volitions, specified by these principles, bearing upon the reflexive goods themselves. To be alive to any form of harmony, to be interested in it, and to choose for it, one must have practical knowledge of it as a good to be realized. The choices included in the instantiations of reflexive goods cannot be part of the data for understanding the principles of practical knowledge directing toward these goods. Thus, while some of the first principles of practical knowledge presuppose volitions, none of them presupposes the volitions whose objects it provides.

Just as theoretical knowledge, true opinion, and experience enhance the initial insight into the substantive goods, so they deepen understanding of the reflexive goods. For example, both sound metaphysics and experience in practicing authentic religious faith contribute to one's understanding of the good of religion. In doing so, they enhance the power of the practical principle underlying the religious quest [section $\mathrm{XII}(\mathrm{A})]$ :

However, one's understanding of the reflexive goods also is affected by immoral choices [see section XI(A); XII(C)]. For instance, rather than understanding religion in terms of harmonizing human wills with God's will, people can understand it in terms of bringing a more-thanhuman source of meaning and value into accord with immoral human desires [see section XII(C)]. 


\section{A Corollary: Two Theses about Incommensurability}

Insofar as the basic goods are reasons with no further reasons, they are primary principles. Since they are primary principles, the goods of the diverse categories are incommensurrable with one another.

For, if they were commensurable, they would have to be homogeneous with one another or reducible to something prior by which they could be measured. If they were homogeneous with one another, they would not constitute diverse categories. If they were reducible to something prior, they would not be primary principles: Thus, they are incommensurable: No basic good considered precisely as such can be meaningfully said to be better than another. How even basic interests are naturally ordered to one another will be explained [in section XI(A)].

It follows from this incommensurability that all basic purposes are alike only in being desired for some reason. They differ in desirability because there is no single reason underlying every purpose for the sake of which one acts. Hence, the basic goods of diverse categories are called "good" only by analogy.

Sometimes we have intermingled and confused the preceding thesis with a thesis about a different incommensurability: that between instantiations of goods in the purposes for which one might choose to act. This incommensurability obtains even between instantiations of one and the same basic good. For instance, what makes vacationing at the beach appealing and what makes vacationing in the mountains appealing; what makes committing adultery appealing and what makes remaining faithful appealing - such alternatives are incommensurable. in the sense that each possibility has some appeal not found in the purpose which makes the other appealing. When one has a choice, no option includes in the instantiation of the good it promises everything promised by its alternative-even when the alternative would instantiate the very same basic good.

Clearly, the incommensurability of the diverse categories of basic goods and that among prospective instantiations of goods are different. For the second incommensurability is present even where the same interest make both alternatives choiceworthy-for example, when someone who has only one set of reasons for taking a vacation chooses between mountains and beach. Here the incommensurability of the categories of goods is irrelevant, and so the relevant incommensurability is plain: The benefits anticipated somehow differ. Neither one's purpose in choosing to vacation in the mountains nor one's purpose in choosing to vacation at the beach of fers in every respect a more adequate instantiation of those basic goods which are one's ultimate reasons to vacation. 


\section{Dialectical Defense of First Practical Principles}

\section{A. Dialectics: Theoretical Knowledge}

The self-evidence of the principles of practical knowledge does not preclude their being rationally defended. One can argue for a propostion without using a middle term to prove it. Dialectical arguments relate a proposition to be defended to other knowledge, and show that denying it has unacceptable consequences.

The dialectical defense of the basic goods is a theoretical project. It presupposes natural, nontheoretical knowledge of the first practical principles, which are the subject matter of this theoretical reflection. Hence, the knowledge of these practical principles as practical in no way depends on these theoretical arguments. As we have said, the practical principles are self-evident truths, not conclusions from theoretical knowledge about human persons.

However, it is worth recalling that theoretical knowledge is relevant not only to the defense of the first practical principles, but to their function in guiding action. Theoretical reflection deepens understanding of the basic goods, and knowledge about facts bearing on their instantiation is necessary to pursue them effectively. For instance, one cannot effectively promote health without knowing biology, nor can one effectively pursue friendship with God without knowing (by reason and/or faith) at least some truth about God. Moreover, one needs theoretical knowledge about one's powers and actual situation to know what one might choose to do.

\section{B. Dialectical Defense: Ineligible Candidates}

Attempts to add candidates to the list of basic goods can be dealt with dialectically. However, there are many plausible candidates which are in different ways closely akin to basic goods. So the argument, fully developed, would be quite lengthy, and we only sketch it out.

There are intelligible goods which are not basic-for example, winning, being free to do as one pleases, being wealthy, and so on. These are instrumental [section II(B)].

There also are intelligible aspects of basic goods, which provide reasons adequate to motivate actions, but which are not themselves the complete reality of any fulfillment of persons-enjoyment, tension reduction, and so on. These are only parts of basic goods, and by themselves they fall as far short of being rationally desirable as the goods, of which they are parts, are wholes greater than these parts.

There are basic motives which are not intelligible goods-for exam- 
ple, pleasure and pain. Insofar as these are not intelligible goods, they provide no reason for acting. However, states of affairs which include them often instantiate a basic good or its contrary-the reflexive good of inner peace or its contrary, inner disturbance. Feeling pain usually is disturbing. But pain itself is naturally beneficial, inasmuch as it is a necessary signal, whose absence would impede every effort to maintain and promote health. Obviously, too, a state of affairs including pain often instantiates some basic good-for example, playing a strenuous game well.

One can imagine a state of affairs ("perfect happiness") such that if it were realized one enjoying it would have no further reason for doing anything except those actions which contributed to or constituted it. But, perfect happiness, being a state of affairs, would be a purpose rather than a reason for action, and so would not be one or all of the basic goods. Rather, if it were realizable, perfect happiness would promise the supreme benefit of action, and all the basic goods would be reasons for acting for it. (We shall argue [in section $X(A)$ ] that the nearest thing to what good people mean by "happiness" is the ideal of integral human fulfillment-a state of affairs which human actions cannot realize.)

There are personal qualities such as dignity and self-respect which embrace globally all or many aspects of personal fulfillment considered from the point of view of important relationships with other people or oneself. Such goods are not basic goods; they can provide reasons for acting only insofar as the goods which underlie them can do so. The point can be clarified by considering dignity and self-respect more carefully.

Dignity is primarily the worth of persons as persons, compared with everything subpersonal, and secondarily the worth of persons superior in various ways to others. Such personal worth or superiority cannot be directly realized or harmed through human action. However, the dignity of persons can suffer insofar as various aspects of personal fulfillment can be damaged or lost-for example, through the unfairness of others or through ill fortune. The various intelligible goods can then provide reasons for acting to protect or promote the person's fulfillment conceived of as dignity. For example, if a woman's dignity is damaged because she lacks the employment she needs to support her family, the only way to help her recover her dignity is by helping her find suitable work.

Similarly, self-respect is one's awareness of and satisfaction with one's fulfillment, judged by standards. one accepts. In itself, it is an aspect of the goods which underlie it considered together. Thus, one acts for 
it by acting for those goods. So, if an alcoholic loses self-respect as he sinks into the gutter, the only way to regain it is by regaining the health and moral integrity which his alcohol abuse has damaged.

Self-respect also is an intelligible good insofar as it is instrumental to the pursuit of all other goods, since one lacking it is emotionally disabled from energetically pursuing them.

\section{Dialectical Defense: Genuine Practical Principles}

One way to argue for the first principles of practical knowledge is by considering actions and seeking their reasons. We identified this line of argument [section III(A)] as the proper method of locating the basic goods, to which the principles of practical knowledge direct actions. However, there are three other lines of dialectical argument which one can use to defend these principles.

First, theoretical studies of human persons, including empirical psychology and philosophical anthropology, uncover the natural inclinations. Some of these theories-for example, Freudian psychology, structuralist anthropology, behaviorism, dualistic philosophies of the person-are very inadequate. But the body of material taken as a whole testifies to natural inclinations to stay alive and healthy, to know, to do good work and to play, to get along with others, to be at peace with reality, and to get oneself together. Accepting the list of basic goods is supported by the data; rejecting it is at odds with the data.

Second, the very possibility that anthropological study can examine every culture points to underlying common starting points of cultural development. Anthropologists can look for and find the diverse ways in which peoples keep themselves alive, seek and hand on knowledge, attempt to maintain harmony among their own members, try to get right with the more-than-human source of meaning and value, and so on. Accepting the list of basic goods as first principles of action explains how the anthropological enterprise is possible, whereas claiming that all human values are culturally conditioned renders the enterprise inexplicable.

Third, attempts to remove some of the candidates from the list also can be dealt with dialectically. For example, some think that, while life is an intelligible good, it is only instrumental not basic. However, any attempt to establish this can be shown to involve a theoretically indefensible dualistic account of the person. Again, truth might be considered entirely instrumental, but any attempt to argue for such a theory can be shown to presuppose the basic goodness of knowing theoretical truth, and so to be self-defeating. 


\section{Persons: Why Basic Goods Motivate}

\section{A. Basic Goods and the Fulfillment of Persons}

Why is it that the basic goods are the ultimate reasons for acting? Why do these goods have motivating power?

These are theoretical questions. In trying to answer them, we are not trying to deduce first practical principles; that cannot be done. Rather, we are continuing our dialectical defense of these principles, by explaining how basic goods are both one with and distinct from persons, who, therefore, in one respect are and in another are not the ultimate reason for every human action.

Any creature which acts is one whose reality is not fully given at the outset; it has possibilities which can be realized only through its acting. The basic goods are basic reasons for acting because they are aspects of the fulfillment of persons, whose action is rationally motivated by these reasons.

Does that mean that every rationally motivated action is done for the agent's individual self-fulfillment? No. As intelligible, the basic goods have no proper names attached to them. So they can be understood as goods and can provide reasons for acting whether, in a particular case, the agent or another will benefit.

Many actions are done by two or more persons acting together; the basic goods which motivate actions can be realized in all those acting, but need not-for example, a physician and patient may act together for the patient's health. Community in action also can embrace someone not at the moment a contributing member who is socially united with those who at present act for his or her benefit. For example, a couple can act for the coming to be and growing up of a child.

The objects of feelings, which are among the data of the principles of practical knowledge, do not have the universality of intelligible goods. Yet it does not follow that feelings are egoistic. Feeling motivates to action for sensible goods which will be realized in the agent and/or in individuals concretely related to the agent-for example, feeling motivates food gathering by animals for themselves, their mates, and offspring. However, animals' action does not involve the reflexivity needed to distinguish the agent's self from the selves of others benefited by an action. Thus, there is no "I" and "you" for animals and little babies.

So, the basic goods are motives for action in virtue of their being aspects of the full-being of persons without that entailing that human action is fundamentally egoistic. Living egoistically and living in communion with others are both possibilities, given the structure of human 
motivation. Therefore, it begs the question to assume that human motivation is fundamentally egoistic, and that a nonegoistic normative theory must show how to transcend this gratuitously presupposed fundamental egoism.

\section{B. Persons Themselves and the Basic Goods}

The basic goods of the diverse categories provide diverse reasons for choices which fulfill persons in diverse ways. Health, playing tennis, and marriage plainly fulfill different aspects of a healthy, tennisplaying, married couple.

Are we saying that the basic reasons for acting simply are personsindividually and in communion? Yes and no.

Yes, in the sense that in acting one primarily loves persons, oneself and others with whom one is somehow in community and who one hopes will benefit from one's actions. In acting for the basic goods, one's hope simply is to foster them in and for persons. In the fullest sense, one loves (and such love includes feeling) the whole person, including both the person's given reality (here love is not practical but is contentment or joy) and whatever still may be hoped for as that person's fulfillment.

But no, because the already existing reality of persons simply does not depend upon human action. So, the reasons for acting are more limited-the basic goods. These are not the whole reality of any individual or community, but those intelligible aspects of the fulfillment of persons (as individuals and in communion) to which human actions can contribute.

Thus, one loves in a secondary sense (1) the basic goods themselves and (2) their instantiations. For they are (1) what one is fundamentally alive to and (2) intends as benefits for persons.

\section{Practical Truth}

\section{A. Practical Truth's Adequation}

The truth of theoretical knowledge is in the conformity of propositions to prior reality, actual and possible. This truth is signified by "is": So it is. The truth of practical knowledge, beginning with its self-evident principles, is not signified by "is" but by "is to be"-for example, Good is to be done and pursued.

The reason for this difference is that what is known by practical knowledge has its reality, not prior to that knowledge, but through it. In coming to know theoretically, one comes into accord with prior 
reality. But in coming to know practically, one becomes able to bring something into reality. It follows that practical knowledge cannot have its truth by conformity to what is known. Rather, a practical proposition is true by anticipating the realization of that which is possible through acting in conformity with that proposition, and by directing one's action toward that realization.

Some may reject this account of practical truth, on the assumption that "truth" can only mean conformity of knowledge to subject matter, adequation of mind to reality-in other words, that "truth" is used correctly of practical propositions only if it is used with the same meaning it has in speaking of theoretical propositions. One who takes this position tries to reduce practical to theoretical knowledge. However, "is to be" cannot be uniformly replaced by "is." (One cannot even try to reduce practical to theoretical knowledge without thinkingpractically-that such a reduction is to be carried out.)

Others may concede that practical propositions concerning particular acts to be done find their truth in their anticipation of what is to be realized through action, but insist that the truth of the first principles of practical knowledge must be in their conformity to prior reality: the possibilities opened up by human nature. This position would leave practical propositions concerning particular acts to be done without any principles homogeneous with them. However, these propositions need such principles, for their directiveness, which plainly is derivative, logically cannot come from purely theoretical principles [section I(B)].

Thus, "truth" is said of practical propositions by analogy. Practical propositions, including first practical principles, are true by anticipating the fulfillment possible through action in conformity with them and directing action toward that realization; practical propositions are not true by conforming to anything. But, it will be objected, every possible human fulfillment plainly is grounded in human nature.

We agree that practical knowledge and freedom are not the only necessary conditions for fulfillment. The possibility of human fulfillment also presupposes both the given reality of human nature-with its capacities and natural inclinations-and people's actual abilities, skills, and resources, together with the challenges and opportunities offered by the real world in which humans live their lives. In general, what still can be presupposes what already is; in particular, what one naturally is grounds all that one is to be.

However, not only the realization but the specification and projection of one's possible human fulfillment depend on more than given human nature. For human nature also includes the capacities of practical knowledge and free choice, and these not only enable a person 
to realize possibilities which are defined independently of their exercise, but to define and project possibilities in and through their exercise. Thus, not only the actualization of the possibilities of human fulfillment but those very possibilities themselves partly depend upon human persons' practical knowledge, free choices, carrying out of these choices, and the results of carrying them out. For example, a person can be virtuous or, failing that, can become vicious, and the very possibility of being either-not merely the fact of being one or the otherpresupposes practical knowledge, freedom, and action.

In sum. What human persons can be through their freedom and action depends on practical knowledge rather than vice versa, and so the adequation which is the truth of practical knowledge is not conformity to some already existing order. The adequation of practical knowing is not that of theoretical knowing, namely, conformity of knowledge to known. But neither is it a merely formal truth involving a "conformity to its own structures" or something of that sort. The truth (that is, the adequation) of practical knowledge is the conformity of what is to be through knowing to the knowledge which will help to bring it about.

Since "true" is said in radically diverse senses of theoretical and practical knowledge, someone might ask whether there is any basis whatsoever in reality for speaking of "truths" in both cases. There is. For although the relationships between the human mind and its objects are opposite in the two cases, truth in either case means that both the human mind and its objects conform to the mind of God, who makes many things true apart from human practical knowledge, free choice, and action, but makes some things become true only with and through this particular type of secondary causality.

\section{B. Human Fulfulment: Neither Found Nor Made}

Against this account of practical truth, someone may argue: "There really are only two possibilities: Human persons must either (1) find and theoretically know in advance the possible fulfillment to which the is-to-be of practical knowledge points (and only realize this possibility through practical knowledge of it and action for it), or (2) somehow by their practical knowledge make (that is, invent and fashion) their own fulfillment's very possibility, not merely its realization. Plainly, the second is absurd, for human persons are not beings without an essence, who can be and flourish as anything whatever by some impossible process of self-creation. Therefore, one must accept the first alternative." 
However, the dichotomy is false. Human persons do not find and theoretically know in advance the possible fulfillment to which the isto-be of practical knowledge points. But neither do they invent and fashion their own fulfillment's very possibility-as if there were some sort of creative art or technology for living human life. The true alternative is: Beginning from first practical principles, which human persons neither select nor fashion, they develop their fulfillment's possibility. In this development, practical knowledge anticipates the possible fulfillment-which is to be-to whose realization it guides action.

Theoretical knowledge of this possible fulfillment begins and grows only as it is unfolded and actualized. Persons cannot know just what they can become as persons before they become-that is, act and know the fruit of acting. If the preceding theoretical statement seems strange, its strangeness is easily dispelled by going back to the relevant phenomena.

For example, by a first principle of practical knowledge, one knows that it is good to know, and one is therefore alive to knowing. This simple volition bears upon everything one can ever know. But one does not thereby find and know in advance the possibility of human fulfillment through knowing - to what knowing might extend and what it will be like as it gradually unfolds (perhaps for millions of years to come).

Yet because of one's anticipation of and interest in knowing certain sorts of things, one recognizes as choiceworthy many possible actions one might do for the sake of knowing. Available options, which depend on one's endowments and opportunities, are known in advance, and part of this advance knowledge is theoretical-for example, that we could proceed with our research in this way.

But the possibility of action and that of fulfillment through it are not identical. When one is interested in knowing, one is not primarily interested in what one can do by way of inquiry (or even in what one can be in carrying on the inquiry). Rather, one is interested in knowing what one will know, and in becoming what one will be, if one's inquiry succeeds. But precisely insofar as inquiry succeeds, one comes to know not only what one did not know beforehand, but also the fulfillment which practical knowledge anticipated in knowing that knowing is a good to be pursued. Once one goes beyond the knowing which occurs without deliberation and choice, one can only find out what one can know and what knowing really is by trying.

One might suppose that this example works only because it concerns knowledge. But there is a similar ignorance in all anticipations of any of the benefits one hopes for in acting through choice by reason of any of the basic goods. 
Even in acting for health, although one knows what it is to feel well, one hopes for something more than that. One anticipates a certain smooth functioning, without knowing exactly what will constitute it. One has a choice whether and how to act-what regimen to adopt, what treatment to accept, and so on-because one cannot tell in advance exactly what benefit any particular action may yield.

Again, an engaged couple who are committed to building a happy marriage cannot predict what their marital friendship will turn out to be like as it unfolds. They will learn what the anticipated and intended benefits really are only by faithfully keeping their mutual commitment.

\section{The First Principle of Practical Reasoning}

The special character of practical truth can be further clarified by considering the first principle of practical reasoning, and seeing how it functions as a principle.

Every reasoning process which terminates in nonhypothetical truths presupposes self-evident first principles as its most basic premises. But every reasoning process also presupposes a self-evident first principle which does not serve as a premise-the principle of noncontradiction. No first principle which serves as a premise can be a principle of all reasoning, because the whole family of reality (about which one can reason) is not of one genus. But the principle of noncontradiction is a principle of all reasoning.

How does the principle of noncontradiction function as a principle of all reasoning? By prohibiting incoherence. Thinking can be incoherent, and the principle of noncontradiction cannot prevent that. But it does function as a norm of thinking by requiring that incoherence be eliminated when it is discovered. Incoherent thinking cannot contribute to genuine knowledge because reality, unlike thinking, cannot be inconsistent. Thus, by prohibiting incoherence, the principle of noncontradiction makes its proper and indispensable contribution to knowledge.

In demanding that incoherence when discovered be eliminated, the principle of noncontradiction exercises a certain priority over all selfevident first principles which are premises, for it puts them to work. It does this by demanding a reevaluation of any incoherent pair of propositions which one had considered true. Such a reevaluation of the contradictory pair of propositions will use as a standard something one thinks is, or is reducible to, some self-evident principle.

The principle of noncontradiction operates in practical as in all other reasoning. But another self-evident first principle, Good is to be done and pursued, operates in all practical reasoning. Unlike the first prac- 
tical principles which serve as premises, it is like the principle of noncontradiction in not serving as a premise. For just as being is not a single genus, so the good is not a single genus [section III(C)]. That which arouses interest-goodness-can be instantiated through action only by the action's bringing about a benefit of one or another category.

How does the first principle of all practical reasoning function as a principle? By prohibiting pointlessness. The point of practical knowledge is the intelligent direction of action toward human fulfillment, and this point can be lost even though practical thinking goes on, just as thinking in general can go on despite its incoherence.

For example, people who have failed to do what in some sense they should have done often pointlessly deliberate about what they might have done, even though they do not think their reasoning can intelligently guide their action toward any benefit. Again, inasmuch as actions should embody practical knowledge, people often become aware of pointlessness when they continue to do something habitually after it no longer promises the benefit it once provided. Although the emotional motive is still effective, one can recognize the pointlessness of one's action: "It's silly to keep on doing this, but ....."

Thus, the first principle of practical reasoning does not prevent pointlessness. But it functions as a norm by directing that pointlessness be eliminated when it is discovered. In demanding that pointlessness be eliminated, the first, common principle of practical reasoning exercises its priority over the self-evident principles which are premises. It does this by requiring that every deliberate action be undertaken ultimately for the sake of some benefit-that is, something in which one is basically interested because one is directed to it by a practical principle which is a premise of one's practical knowledge.

Practical knowledge directs to the fulfillment possible through action, and benefits constitute this fulfillment. So pointless thinking, which cannot direct action toward realizing any benefit, adds nothing to the knowledge of practical truth. If pointless thinking is coherent, it does not fall short of truth and falsity in the way that incoherent thinkingwhether theoretical or practical-does. However, since it does not direct action toward bringing something into conformity with a practical proposition, pointless thinking falls short of practical truth and falsity. Therefore, by prohibiting pointlessness, the first principle of practical reasoning makes its appropriate and indispensable contribution to practical knowledge. 


\section{Part Two: Moral Truth}

\section{Vil. From Practical Principles to the Moral Ought}

\section{A. The First Principle of Morality}

Although the first principle of practical reasoning prohibits pointlessness, it does not in the same way prohibit every sort of unreasonableness in practical thinking.

Even morally bad actions have their point. One chooses to do what is morally wrong for some reason, and like any other deliberate action, the reason for which one acts immorally must ultimately be reduced to the basic goods. So far forth, even an immoral act responds to the first principle: Good is to be done and pursued.

However, morally wrong acts do not respond to this principle as perfectly as morally good acts do. To see why, one must consider the relationship between the principles of practical knowledge and those of morality.

In prohibiting pointlessness, the first principle of practical reasoning as it were demands: Take as a premise at least one of the principles corresponding to the basic goods and follow through to the point at which you somehow instantiate that good through action. This demand is minimal and leaves one free to do anything from which one can anticipate any benefit whatsoever.

One can imagine another principle making a far stronger demand: Insofar as it is in your power, allow nothing but the principles corresponding to the basic goods to shape your practical thinking as you find, develop, and use your opportunities to pursue human fulfillment through your chosen actions. This stronger demand is, not only that one be reasonable enough in one's practical thinking to avoid pointlessness, but that one be entirely reasonable in such thinking.

This stronger demand is inconsistent with many possible choices consistent with the weaker demand. The possible choices excluded by the stronger demand are those which are immoral, for the stronger demand is a way of expressing the first principle of morality. This expression of the first moral principle makes it clear that to be morally good is precisely to be completely reasonable. Right reason is nothing but unfettered reason, working throughout deliberation and receiving full attention.

Unfortunately, reason is not always unfettered. Basic goods are not the only source of motivation for rationally guided actions. Only emotionally appealing possibilities come up for deliberation, and feeling also is necessary to carry out any proposal one adopts by choice [sec- 
tion II(C)]. Since what is emotionally satisfying is not identical with but, at best, only part of what fulfills persons as such, feeling can and often does tend to motivate actions to goals more limited than the benefits for persons which practical knowledge proposes to be sought through action. The part can compete with the whole; satisfying the desires of the part can frustrate the interests of the whole.

\section{B. How Possible Purposes Arise}

It is worth looking closely at the process by which immoral choices come to be made. But first it is necessary to consider how possible purposes arise.

No choice ever is made unless one considers at least two incompatible possibilities: doing this or not doing it, doing this or doing that. For such deliberation to occur, one must have mixed feelings, which provide some motivation toward possible goals of action whose joint realization is inconsistent. One hesitates, looks for a way to dissolve the conflict, finds none, and becomes aware that a choice is needed.

The purposes of rationally directed actions are sometimes first urged by desire arising out of simple volition of basic goods and sometimes first urged by desire arising from feeling. For example, a physician interested in improving people's health may first think of the benefit promised by a particular project and only gradually become enthusiastic about pursuing it as a goal. But a patient seeking treatment may first have the goal of getting rid of unpleasant symptoms, and only with instruction appreciate the benefit of doing what is necessary to regain health.

Sometimes possible goals are fashioned by imagination under the direction of reason. Sometimes they are generated independently of reason. And sometimes each source contributes to an inconsistent set of possible goals.

Aside from those which presuppose a prior immoral choice, possible goals fashioned by imagination at the behest of reason cannot in themselves pose a challenge to reason. (Even so, as will be clear shortly, it can be wrong to choose to pursue them.) For the origin of such goals is in reason's own principles, by way of volitions, beginning with the simple volitions which the principles of practical reason specify. The purpose of the possible action proposed for choice includes a benefit whose prospect generated the goal; interest in that benefit preceded the emotional desire for the goal. Sometimes two purposes of this sort require one to make a choice, simply because one cannot act for both. Such choices are between morally good alternatives. 
Sometimes a possible goal is generated independently of reason but is readily understood in terms of the principles of practical knowledge, so that the anticipated benefit could just as well have led reason to direct imagination to fashion that goal. For example, someone trying to finish some work in the garden on a winter day begins to think about going inside and leaving the work to be finished some other day. The goal of getting out of the cold, generated without reason's help, is readily understood as avoidance of dangerous overexposure-a purpose which could as well have been suggested by one's rational interest in staying alive and well. Thus, in such cases, too, the goal in itself poses no challenge to reason, and so one can choose to act for the purpose which includes the goal without fettering reason.

Sometimes, however, one chooses between an alternative generated in either of the ways just described and a possible action whose purpose will have been synthesized in a different way. The latter action, if chosen, will be rationally guided to its purpose; still, its goal will be gained at the expense of reason, part of whose directiveness will have been ignored by choice.

\section{How to Make Immoral Choices}

One can easily see how an immoral choice is made if the goal is set by some previous immoral choice. But it also occurs when a goal generated independently of reason leads one to synthesize a purpose of a peculiar sort. This sort of purpose is one for which a person cannot choose to act without that choice bearing upon other benefits and harms in a way different from that which unfettered reason would direct.

For example, hatred and anger suggest the goal of some harm to another.

The principles of practical knowledge of themselves always direct to the opposite-to benefit persons, both oneself and others. Moreover, these principles direct one to live at peace with others and to avoid hurting oneself, and everyone knows from experience that harming others is likely to have consequences contrary to these interests.

Still, in one or more of the basic goods one can find reasons which enable one to anticipate certain benefits from taking revenge-for example, that it will discourage future provocations and so make for more peaceful relations ("He'll never dare do that to me again!") or that failure to take revenge would be unjust ("It would be a crime to let her get away with that!').

One can know very well that such benefits are not reasonably anticipated here, and that, hostile feelings aside, one surely would not 
deliberately cause harm as one is tempted to do. Still, the unreasonableness of choosing to harm another can be ignored, for one never knows just what benefit can be achieved until one tries. And from the emotional point of view, there is no question that revenge would be sweet. This sweetness also can be understood as part of the potential benefit of vengeful action. For taking revenge will mollify hurt feelings and bring harmony between them and one's choicesince that choice will be in accord with one's feelings!

Thus, the vengeful person chooses, fettering reason by means of one of its own practical principles: that which directs toward the harmony of feelings with one another, and with judgments and choices.

Not all immoral choices come about in exactly the same way. Sometimes the action's purpose is morally sound: The goal poses no challenge to reason, the benefit is real, and similar acts can be chosen in other circumstances without any restriction of reason.

For example, in a public library, one sees a new novel one has been wanting to read, charges it out, and brings it home, having the goal of reading it and intending the benefit of esthetic experience. Thus far, no problem.

But one found the novel on a reserve shelf waiting to be claimed by another patron, and discarded a six-month waiting list, which had been attached to the book, before charging it out. The anticipated benefit, to be realized in oneself, is sought at the expense of others. And one knows that people cannot hope to live together in harmony if they treat one another as they themselves do not wish to be treated. Practical knowledge directs to fulfillment, which is reasonably anticipated only in community with others. Thus, feelings aside, one would not discard the waiting list and check the novel out.

Still, one is eager to read the novel, and so one can suppose that little harm need be anticipated to others if they must wait a while longer, that one has not used the library heavily of late and deserves a "fair share" of its resources, that the librarians are at fault for not providing extra copies of such a popular book and so on. A choice to take the book home satisfies one's eagerness to read it, and so brings harmony between feelings and choice.

The selfish person reasonably anticipates the same benefit as might have been derived from a similar act chosen without setting aside the interests of others. Nevertheless, like the vengeful person, the selfish person in choosing fetters reason by abusing one of its own practical principles.

In sum. If feelings simply determine action, then that action is not rationally guided, and so in itself is neither morally good nor evil. But 
feelings can impair the rational guidance of an action without determining it. They do this by proposing goals whose pursuit can be made into a purpose of rationally guided action, but only by a free choice which fetters reason and limits its directiveness.

\section{The Emergence of the Moral Ought}

Immoral choice fetters reason by adopting a proposal to act without adequate regard for some of the principles of practical reason, and so without a fully rational determination of action. And so, when an immoral choice is made, the principles of practical knowledge are embodied less perfectly than they would be if a morally acceptable proposal were adopted. This point deserves further consideration.

When practical knowledge is confronted with the tendency of feeling to restrict it by urging a possibility whose choice would fetter it, the is-to-be of practical knowledge becomes ought-to-be. The directiveness of practical knowledge becomes normativity because what is to be might not actually come to be and yet still rationally is to be. Of course, there is some reason in the basic goods for choosing the immoral possibility, and so it also is considered a purpose which is to be. But the ought-to-be which calls for morally right choice represents the full directiveness of the principles of practical knowledge, while the is-to-be which commends the morally wrong choice represents only a fragment of that directiveness operating in isolation from the whole.

Hence, it is clear in what sense morally wrong acts do not respond to the first principle of practical reasoning as well as good acts do. Since that principle underlies the directiveness of all the basic goods, it is embodied in morally wrong actions insofar as they are formed by that directiveness. But only morally right choices respond fully to all of the principles of practical knowledge. Thus, only morally right choices respond perfectly to the first principle of practical reasoning.

\section{Vili. Moral Truth: Comparisons and Contrasts}

\section{A. Practical Truth, Moral Truth, and Moral falsity}

The truth of practical knowledge with respect to its first principles is their adequation to possible human fulfillment considered precisely insofar as that fulfillment can be realized through human action [section $\mathrm{VI}(\mathrm{A})$ ].

Moral truth is a kind of practical truth.

Kinds within a genus often are differentiated by the addition of some further intelligibility. But moral truth as a kind of practical truth is not differentiated from moral falsity by the addition of any intelligibility 
other than the intelligibility proper to practical knowledge as such. Rather, moral truth is differentiated by the integrity with which it directs to possible human fulfillment insofar as that can be realized by carrying out choices. Thus, moral falsities-for example, "That so-and-so should be wiped out" and "One must look out for number one"-are specified by the incompleteness due to which they lack adequacy to possible human fulfillment insofar as that can be realized by carrying out choices.

Consequently, (1) moral truths and (2) moral falsities are differentiated by their opposed relationships to the whole set of practical principles, which can be brought to bear in practical judgment either (1) integrally or (2) only selectively.

Reality as a whole, which metaphysics studies, has some ontological conditions superior to human reason and some inferior to it, and soHegel to the contrary notwithstanding-the theory that truth is coherence is bad metaphysics. But the moral domain has no proper principle other than the principles of practical knowledge itself, although its ultimate principle is beyond human reason [section $\operatorname{XII}(A)$ ]. Therefore, in the moral domain truth is the whole, and falsity is a part, abstracted from the whole and thereby made to rationally guide action in a misguided way, just as if the part were by itself the whole.

\section{B. Practical Truths Which Are Not Moral Truths}

Practical truths which are not moral truths are of two kinds. Of one kind are practical principles-for example: Knowledge is a good to be pursued-which fall short of integral adequacy to human fulfillment only because their proper directiveness is no more than an element of the directiveness of practical knowledge as a whole.

Practical truths of this sort are operative before moral issues arise. They are necessary conditions for the simple volition which gives rise to deliberation. So far forth, practical principles can be called "premoral."

But, as we have explained, the several practical principles are moral principles when the whole set of practical principles works together and constitutes the integral directiveness of practical knowledge. Thus, practical principles never lack the moral relevance which emerges when moral issues arise. So far forth, practical principles can be called "moral."

The other kind of practical truths which are not moral truths are moral falsities. Just insofar as moral falsities do give some rational direction to an action, they are practical truths. Action in their light 
is not pointless, but fruitful in realizing some benefit (though miserable), some fragment (though mutilated) of integral human fulfillment.

Practical truths of this sort operate by secession from moral consideration. So far forth, the practical truth of moral falsities can be called "amoral." But such partial truths can never escape their moral falsity. So far forth, their effectiveness in practical thinking is better called "immoral."

\section{The Relationship between OUGHT and Is}

In view of the preceding account of practical truth and moral truth, it should be clear why one cannot derive the moral ought from any theoretical is.

The moral ought cannot be reduced to the is-to-be of practical truth without eliminating the distinction between the directiveness of a practical judgment that something immoral is to be done and the normativity of the moral truth that it should not be done. The is-to-be of practical truth cannot be reduced to the is of human nature without eliminating the distinction between, on the one hand, action and fulfillment through it, and, on the other, what persons are by nature, prior to their exercise of free choice.

Still, this twofold irreducibility does not mean that morality is cut off from its roots in human nature. For the normativity of the moral ought is nothing but the integral directiveness of the is-to-be of practical knowledge. And any adequate theory of human persons will include among its true propositions: Everyone who does rationally guided actions naturally knows the first principles of practical knowledge and naturally wills (by simple volition) the goods to which they direct. In this sense, the is-to-be of the first principles of practical knowledge is itself an aspect of human nature.

\section{Formulations of the First Moral Principle}

As we have formulated and developed our basic normative theory over the years, we sometimes presented it without offering any explicit formulation of the first principle of morality.

On those occasions, we began with an account of the principles of practical knowledge corresponding to the basic goods and moved directly to moral principles such as those requirements of practical reasonableness which demand fairness, forbid revenge, exclude doing evil to achieve good, and so forth. These intermediate moral principles are the modes of responsibility. They do not refer to any specific kinds of acts, but 
they are more specific than the first principle of morality, because they specify, in several ways, how any action must be willed if it is to comply with the first principle of morality. Although modes of responsibility presuppose the first principle of morality, we have sometimes presented them as if they were direct implications of thoroughgoing practical reasonableness.

The preceding explanation [sections VII(A); VIII(A); VIII(C)] makes it clear why we sometimes failed to formulate the first moral principle. For that principle merely articulates the integral directiveness of the first principles of practical knowledge, when they are working together harmoniously in full concert.

Some of our attempts to formulate the first principle of morality also have been defective. For example, in several early works Grisez suggested that the basic moral requirement is to act for at least some good and to avoid violating any basic good. This formulation expresses two of the modes of responsibility but fails to express their common ground, which also is the ground of other modes, such as fairness.

Again, some of our works suggested that the basic moral requirement is to choose with an inclusivistic attitude-that is, an attitude which maintains respect for the values which are not chosen. This formulation points to the integrity which in fact is constitutive of moral truth, but fails to articulate the way in which the integral directiveness of practical knowledge constitutes moral truth.

Our current attempt to formulate the first principle of morality is: In voluntarily acting for human goods and avoiding what is opposed to them, one ought to choose and otherwise will those and only those possibilities whose willing is compatible with a will toward integral human fulfillment.

This formulation focuses on the principle of morality insofar as it is the principle of moral goodness which actualizes moral truth. We focused above on the principle of morality insofar as it is the integral directiveness of practical reason. [Sections VII(A-D); VIII(A)]. The relationship between these two aspects of the principle of morality is readily explained.

Moral truth is the integrity of the directiveness of practical knowledge. Ideally, free choices would consistently respond to this full directiveness. Since moral truth points to human fulfillment, ideally the freely chosen actions shaped by moral truth would bear fruit in the fulfillment of all persons in all the basic goods. This ideal community is what we mean by "integral human fulfillment." A good will is one fully responsive to thoroughgoing practical reason. Therefore, the morally good will is a will toward integral human fulfillment. 
This ideal of good will implies intermediate moral principles-the modes of responsibility-from which specific moral norms can be deduced. Thus it enables one to bring the integral directiveness of practical reason to bear upon choices.

\section{Virtues and Moral Principles}

\section{A. The Priority of Moral Principles}

Up to this point, we have not talked about virtue. As we have shown [sections VII(A-D); VIII(A)], the first principles of moral truth are the principles of practical knowledge, and so the virtues cannot be first principles of moral truth. But we do consider virtues to be essential to moral life, because they are aspects of a person who is (more or less) wholly integrated with moral truth, and only such a person can live a morally good life.

Apart from the theoretical inadequacy of attempting to reduce moral truth to the virtues, such an attempt also is unsatisfactory from the practical point of view. For ethical reflection really is helpful only if it can examine and criticize the assumptions underlying accepted virtues and vices. Reflection which takes a way of life for granted, as Aristotle, for example, did, fails to overcome the inadequacies in a society's political structure, religion, and so on which prevent its morally good members from attaining, or even accurately conceiving, the true happiness to which their hearts are open.

Virtues can be evaluated by moral principles. Virtues are character traits, which organize the various aspects of the complex human personality. The ordering of these aspects establishes some form of harmony among feeling, judgment, choice, performance, and so on. Such harmonies are themselves realizations of basic goods. But the quality of these realizations depends on the extent to which they embody moral truth. Hence, only those character traits are true virtues which realize harmonies within the personality acccording to the demands of moral truth.

Of course, these demands must be brought to bear. The very general theory of moral truth proposed above is not sufficient to do that. Nor can specific moral norms, even if assumed as certainly true, serve as an adequate standard for judging character traits, whose range will always extend beyond particular types of action. However, as we briefly indicated above [sections. VII(C); VIII(D)], there are intermediate emoral principles-the modes of responsibility. These are specifications of the first principle of morality, and, in turn, provide premises for deducing specific moral norms. They also provide a standard by which one can evaluate character traits, to see which are genuine virtues. 
For example, an element of character which too often affects the treatment of evildoers is the disposition to exact retribution out of anger and hatred. (Think of those arguments for capital punishment which have no principle but such passions.) In evaluating character traits to distinguish true justice from its counterfeits, one standard is the mode of responsibility that one should avoid taking revenge. By this standard, a character trait which involves the disposition to exact retribution out of hostile feelings clearly is not true justice.

Another of the modes of responsibility is fairness. So, in attempting to discern true justice, one also looks for that harmony between concerns for self and for others which disposes people to act according to the Golden Rule, rather than be satisfied with the conventional justice of their society, which allows them, if free Athenians to use others as slaves, if contemporary Americans to kill their unborn children, and so on.

Although virtues are not primary principles of moral truth, genuine virtues are starting points of morality in the sense that they are conditions for a morally good life. Virtues are aspects of the fully integrated personality of a good person. Such a personality concretely realizes the reflexive goods in accord with moral truth. Hence, such a person is not torn between a will toward integral human fulfillment and desires for mutilated fragments of it, which often have greater emotional appeal. Therefore, such a person can consistently choose what is morally right and fulfill the requirements of a truly happy life-one integrated by a morally good religious commitment [see section $\mathrm{XII}(\mathrm{C})$ ].

\section{B. Virtues and Moral Judgment}

Without having virtues at the outset, people can proceed soundly from practical principles to judgments about what they ought to do. Yet there are two ways in which judgments reached by sound practical reasoning can fall short of full moral truth.

First, in their reflection, people often fail to take into account all available options and other relevant aspects of the situation in which they make a choice. For example, if someone whose interests are at stake is overlooked, a judgment otherwise soundly made is likely to be objectively unfair.

Second, a sound judgment often leaves open which of two or more morally acceptable options will comport best with those concrete aspects of the agent's personality and situation which, because they resist reflective analysis, can be evaluated only by a kind of moral taste or discernment. For example, a sound judgment that one should seek an education leaves open many options. 
Such shortcomings in judgments about what one is to do or ought to do are possible despite sound practical reasoning, because parts of the personality other than the rational part contribute both to one's attention to what is relevant and to one's discernment in the area which resists reflective analysis. Therefore, these shortcomings cannot be overcome without virtues to dispose all aspects of the personality to function harmoniously in the light of moral truth.

\section{How Virtues Can Be Acquired}

It follows that virtues and judgments which attain full moral truth are mutually interdependent. Their interdependence raises the question: How can anyone acquire a virtue?

The answer is that a child whose character is not yet formed can freely choose in accord with a judgment reached by sound practical reasoning. Even if the child's judgment falls short of full moral truth, the child's will, both exercised and formed in such choices, in no way conflicts with moral truth and, indeed, conforms to it, insofar as the child is aware of it. Though character is still undeveloped, such good will is the budding forth of virtue.

Thus, insofar as people choose in accord with soundly reasoned practical judgments, especially in making major commitments, they have the core of the virtues. In carrying out such morally good choices, other aspects of the personality will gradually be drawn into line, errors in moral thinking corrected, and facility in carrying out right choices gained. In this way, virtues are acquired.

In this struggle, people can find some help in sound ethical theory. But they will be impeded by exhortations to embody the morally inadequate "virtues" of the model members of their society. So ethical theory must reduce moral judgments to first principles, rather than treat virtues as if they were irreducible starting points.

\section{Part Three: Ultimate Ends}

\section{Ends Ultimate in Three Diverse Ways}

\section{A. The Ultimate End Rectifying the -Will}

Integral human fulfillment is not individualistic satisfaction of desires or preferences. The ideal of integral human fulfillment is that of the realization, so far as possible, of all the basic goods in all persons, living together in complete harmony [section VIII(D)]. Is not such a perfect community the ultimate natural end of all human persons and communities? 
In a way it is. However, that community would include all persons, past, present, and future. And in the course of history, even in the course of each individual's life, new dimensions of goods unfold. Hence, "integral human fulfillment" cannot refer to a purpose to be pursued as a concrete objective of cooperative human effort. It cannot be anticipated as the outcome of some sort of human billion-year plan.

Moreover, integral human fulfillment is not a basic good alongside the others, nor some sort of supergood transcending all other categories of goodness. For integral human fulfillment is not a reason for acting, but an ideal whose attractiveness depends on all the reasons for acting which can appeal to morally good people.

One way in which integral human fulfillment is the ultimate natural end of persons and communities is that it is the ultimate object of good will. The ultimate object of good will is the ultimate end in the sense that what primarily rectifies the will orders to itself everything else one wills. But how can integral human fulfillment, which is neither a reason for all willing nor an ultimate benefit, rectify the will? How can it even be an object of will?

Integral human fulfillment is not an object of efficacious will. Morally good will, however, is specified (through the integral directiveness of practical knowledge) by the integral appetibility of all the basic goods [section VIII(A)]. Ideally, the fruit of such good will would be integral human fulfillment [see section VIII(D)]. Hence, a person of good will wishes (in accord with unfettered practical reason) for the realization of this ideal, and this wish rectifies the will in choosing.

Moreover, although only an ideal, integral human fulfillment is the nearest thing to what morally good people mean by happiness.

Happiness is usually taken to mean complete fulfillment-that is, having all one's desires satisfied. Everyone has some desires and wishes them to be satisfied. So, reflective persons who are morally good wish for all their morally acceptable actual and potential wishes to be fulfilled.

Such complete fulfillment of wishes, however, is impossible. The fulfilling of some wishes is incompatible with the fulfilling of others; people often must choose among morally acceptable alternatives. Therefore, although everyone wishes for perfect and fulfilling goodin which the will could rest-no one efficaciously wills such a good.

Rather, one at best settles for the happiness which can be achieved through efficacious willing of goods in accord with some specific ideal. For morally good persons, the ideal is integral human fulfillment. They settle for the happiness they have in benefiting themselves and others as they live a morally good life.

The happiness for which a morally good humankind would settle 
would be the most complete possible approximation to the ideal of integral human fulfillment. One can consider the happiness for which morally good persons settle their share in and contribution to this hypothetical approximation. So, although integral human fulfillment is an unrealizable ideal, there is a sense in which it can be considered the morally true ultimate natural end of persons, both as individuals and in community.

\section{B. Basic Goods: Ultimate Reasons for Choosing}

Nevertheless, integral human fulfillment cannot be the ultimate end in the sense of being the ultimate reason why one chooses or should choose whatever one chooses. In this sense, the basic goods are ultimate ends [section II(B)]. But they are aspects of human fulfillment-many, distinct, irreducible - which do not constitute a single ultimate reason why one chooses or should choose whatever one chooses. Is there no such thing?

There would be, if there were some one intelligible good unifying all the goodness of all the basic goods. But there is none. For there is no intelligible principle other than the basic goods to make choiceworthy the possibilities for which persons can act. And the basic goods correspond to the irreducibly diverse components of complex human nature.

But is not God the ultimate end of human persons? The remainder of this paper answers this question. To begin with, God is not the ultimate reason for acting.

The basic goods are reasons for actions [sections II(B-D); V(A)]. In choosing actions to instantiate the goods, one does not find the ultimate reason for one's choices in divine goodness. For, if divine goodness were the reason for one's actions, one's choices for its sake would lead to its instantiation as one's fulfillment, and that instantiation would be through one's actions. But, for two reasons, this cannot be. First, human fulfillment actualizes human possibility, and this possibility cannot be naturally actualized by any nonhuman sort of perfection, not even that of God. Second, human actions cannot lead to the instantiation of divine goodness.

Against the first reason, one might suppose that the human will's openness to anything good, together with its natural dynamism as appetite, somehow amount to a natural tendency toward divine goodness - as it were, amount to a habitual disposition underlying the will's aliveness to the various basic goods. On that supposition, one could naturally will everything else for the sake of divine goodness, which alone, being infinite, could exhaust the capacity of the will. 
However, the truth is that one cannot naturally will everything else for the sake of divine goodness.

For: (1) Nothing is received except according to the capacity of what receives it. But the capacity for the full actualization of anything is determined by its nature. So, nothing receives its full actualization from goodness which does not fulfill its own nature. Now, divine goodness is the actuality of divine nature. Thus, it cannot be the actualization of human persons unless they either cease to be human or become simultaneously divine. Naturally they cannot be both human and divine. Hence, naturally human persons cannot be actualized by divine goodness without ceasing to be human.

But: (2) Human will is a human appetite. Every appetite tends toward the actualization of that of which it is an appetite. So, human will tends to human actualization. Now, nothing is actualized by ceasing to be. But whatever ceases to be what it is, ceases to be. Thus, nothing is actualized by ceasing to be what it is. Hence, human persons cannot be actualized by ceasing to be human.

Therefore: (3) Since human persons cannot naturally be actualized by divine goodness without ceasing to be human (from 1), and since they cannot be actualized by ceasing to he human (from 2), human persons cannot naturally be actualized by divine goodness.

And so the human will can have no natural disposition to fulfillment in divine goodness. In this sense, the hearts of human persons, considered precisely according to their human nature, are not made for God; rather they are made for human fulfillment. If human persons do not rest in human fulfillment, that is partly because they wrongly try to rest in mutilated fragments of it and partly because the human will (unlike the neoplatonic eros) is not for rest.

Furthermore, there can be no natural desire for what is not the natural end of human persons, namely, that vision, promised to those who "are God's children now," by which they "shall be like him" because they "shall see him as he is" (1 Jn 3:2). But Christian faith requires no such natural desire, for, according to it, that intimate vision of God is attained, not through human nature, but by a sharing in the divine nature, received as a gift by "water and the Spirit" (Jn 3:5) or by "adoption" (Rom 8:14-17, 23).

This Christian view that human persons can be given a share in the divine nature is perfectly consistent with the second reason why divine goodness cannot be the ultimate reason for one's actions: that human action cannot lead to the instantiation of divine goodness. For there is a difference between being given something as a gift and achieving it through one's action, and there also is a difference between divine goodness itself and its participations. 
Human actions can and naturally do lead to the instantiation of certain participations in divine goodness.

The will's capacity is not limited to the basic goods, which mark out the finite boundaries of possible fulfillment. For any two options do have it in common that either can be chosen. The ground of their unity in this respect is not the different intelligible goods which make each choiceworthy, but their community in intelligible goodness, for which the will is the appetite. While eacl of the principles of practical knowledge directs that some good be done, all of them in common direct that good be done, and this common aspect of their directiveness corresponds to the will's natural openness to goodness.

For this reason, if one believes that unqualified goodness-goodness itself-is found in God, one will regard him as the source of the goodness of all the basic goods. In this perspective, every human fulfillment is a participation in divine goodness, and every human act is for the sake of divine goodness insofar as one can participate in it by the benefit for which one chooses to do the act. Hence, God can be considered the ultimate end of human persons and communities insofar as their fulfillment in their proper goods is a participation in his goodness.

One might ask whether God is not-or at least for some persons cannot be-the end of human life in a stronger sense than this. The answer is Yes. For among the goods which fulfill human persons and communities are knowledge of God and harmony with him. These ought to be the core of the ultimate end of human life in the sense considered next. [Also see section XII(C).]

\section{The Happiness for Which People Settle}

Not as an ultimate reason for their choices, but in a different sense, persons and communities find their ultimate ends in the fulfillment for which they settle as their approximation to happiness as they conceive it. If this fulfillment is unified, then everything they intend is either a part of it or a means to it. However, not all people have a single ultimate end in this sense.

One might suppose that immoral people necessarily pursue as their ultimate end some one good, such as riches, pleasure, or honor. But an immoral businessman can seek his fulfillment partly in his energetic acquisition of wealth and power, and partly in his exploitative relationships with women, without interrelating the two in any way except by assigning these diverse interests to different slots in his busy schedule.

Even morally good people can live nonintegrated lives. For example, a good ten-year old boy can find some fulfillment in his studies and 
some in playing Little League ball, without integrating these two areas of interest. Morally mature good people, whose lives are largely organized by morally good commitments, also can find fulfillment in some innocent activities which are not integrated with the rest of their lives-for example, a dedicated wife and mother may find some fulfillment by writing poetry in her occasional free moments, without integrating this activity with anything else in her life.

Still, while people need not live in view of anything unified which they settle for as happiness, people should pursue a single ultimate end in this sense [see section $\operatorname{XII}(C)$ ].

And some people do. For example, Christians have in their commitment of faith a principle by which they can organize their entire lives. If they do so perfectly, their every thought, word, and deed carries out their commitment of faith; and so, always keeping the commandments, they love God with their whole mind, heart, soul, and strength, and love all their neighbors as themselves. Such a life fulfills, as perfectly as possible through their action, the wishes of those individuals and that community who live that life (insofar as they do). Therefore, such a life is a happy one, although it falls short of the unrealizable ideal of integral human fulfillment. For those who seek to live that life, the fulfillment it offers is the ultimate end realizable in this life through their human acts. (Christian faith also teaches that the life of faith both depends on God's grace and prepares for his reign, so that acts which make up the life of faith are cooperation toward human fulfillment in the heavenly kingdom [see section XII(D)].)

Yet the integration of one's life toward a single ultimate end is not guaranteed by making a commitment such as Christian faith which can organize one's entire life. For those who have made such a commitment nonetheless seek part of their fulfillment in activities which cannot be integrated by it. For example, Christians sometimes sin while maintaining their commitment of faith. But acts of sin and of faith cannot possibly have the same ultimate end.

The point is clearest in the case of a serious believer who is tempted to make a permanent commitment to a sinful friendship. Such a person may consider the alternatives of abandoning faith, giving up the friendship, or living in sin while trying to practice faith so far as possible. One who chooses the last of these, in that single choice, reaffirms faith for the sake of its ultimate end and adopts a sinful way of life for the sake of its ultimate end. 


\section{Hierarchies and Orders of Values}

\section{A. Natural Priorities among the Basic Goods}

The basic goods of the diverse categories are called "good" in irreducibly different senses, and none of the basic goods can be said meaningfully to be better than another [section III(C)]. It might seem to follow that these basic principles are an unordered crowd which offer no objective standard for setting moral priorities in life. But that is not so.

In three ways, the basic goods are involved in important hierarchies of values. Any basic good is an aspect of the fulfillment of persons, and so is superior to instrumental intelligible goods, which do not perfect persons as such. Any basic good is an aspect of the fulfillment of the person as such, and so is superior to sensible goods, each of which as sensible can fulfill only the sentient nature of a person. Any morally right action for any of the basic goods is superior to every morally wrong action for them, because morally right action contributes to the integral fulfillment of persons and communities while morally wrong action prevents that.

But none of these important hierarchies of values establishes priorities among the basic goods themselves. Thus, it might seem that their interrelationship depends entirely on individuals' free choices, which constitute diverse personal plans of life.

Some statements in some of our previous works may appear to suggest that view. But it is incorrect and incompatible with constant features of the theory developed in all of those works. For prior to anyone's free choice, unfettered practical reason establishes some priorities among one's interests in the different basic aspects of fulfillment.

One of the reflexive goods is harmony among judgment, choice, and performance. If one considers this harmony amorally, one can try to realize it by bringing one's judgments as well as one's performances into conformity with one's choices. However, if one considers this good morally - that is, with practical reason unfettered-one sees that the only way to realize it consistent with integral human fulfillment is by making sure that one's judgments are morally true, conforming one's choices to them, and striving to make one's performances carry out one's choices as perfectly as possible. Whenever one must choose between doing what is morally right and what is morally wrong, one must act according to one's conscience. In doing that, one rightly establishes the priority of one's interest in this form of harmony.

Another reflexive good is harmony among one's feelings and between them and one's choices. If one considers this harmony amoral- 
ly, one can try to realize it by choosing in accord with. one's feelings. However, if one considers this reflexive good morally, one sees that the only way to realize it consistent with integral human fulfillment is by bringing one's feelings into line with one's morally good choices: The fact that one option harmonizes feelings with one's reasonable choice requires one to prefer that alternative to another which simply harmonizes choice with feelings. In choosing the former option, one rightly gives reasonable choice priority over feelings.

The two preceding examples make it clear that interests in the reflexive goods understood from a moral point of view (that is, a completely reasonable point of view) take priority whenever these goods are at stake. But the moral point of view establishes priorities in other, less obvious ways.

No one can live a morally good life without living. The good of life can be pursued only in community with others; indeed, human persons come to be only in community with others who care for them. Morality demands that one play one's proper part in morally good cooperation with others, deal fairly with them, avoid taking revenge, and so on. Thus, without any choice on anyone's part, the good of harmony with others considered morally has as one of its specific forms the elementary community essential for survival. This form of harmony might be called "family solidarity." For children, one thing family solidarity means is obedience. So, for children, obedience to any morally legitimate command of their parents (and those who act on their parents' behalf) should take absolute priority over any other interest.

One could develop other examples to show how unfettered practical reason in various ways establishes priorities among basic interests in goods independently of anyone's situation or choice. Such priorities will hold always and everywhere; they are moral requirements for all human persons precisely as such.

Not all moral responsibilities are constituted by or derived from these natural moral priorities. Many duties arise from prior choices, either one's own or those of others, or from special conditions which do not affect every person. No one who has not wronged another has an obligation to make restitution. No one who has not made a marital commitment has an obligation to be faithful in marriage, and no one simply as a human person has an obligation to make such a commitment. No one who has not come to know truths important to others has an obligation to communicate truths to others.

In sum, while the basic goods, considered as principles of practical knowledge, are not ordered among themselves, it does not follow that these basic principles are an unordered crowd. Prior to anyone's choice, 
unfettered practical reason, together with the conditions which human nature inevitably sets for moral life, establish certain natural priorities among a good person's basic interests. It follows that these priorities set necessary conditions for any morally good life plan.

\section{B. No Hierarchy among the Basic Goods}

This order involving the basic goods, nevertheless, is not a hierarchy among them. It does establish a structure among the diverse aspects of human fulfillment, in the individual person and in community. But the principle of this order is moral truth-the integral directiveness of practical knowledge-not the primacy of any one of the basic goods. Thus, none of these is so absolutely prior that it prevails in every morally good choice.

One might suppose that the reflexive goods, morally considered, have such absolute priority. The most obvious example: The fact that a morally right alternative is right requires one to choose it. However, interest in this reflexive good prevails only in those situations of choice where it happens to be at stake. But in many cases, one chooses among morally acceptable alternatives. And in many other cases, a person can rightly prefer what is morally right, not because it is morally good, but for the sake of some substantive good. For example, a girl, hastening to the playground, chooses to stop to help an old man, who is confused and wandering in a busy street, simply because she intends his safety, not because she realizes her choice to be a moral obligation-a duty she has not yet grasped, although in the circumstances it would be objectively wrong for her to choose to go on to the playground.

It also is worth noting the implications of the fact that the initial understanding of the reflexive goods can be specified not only by moral truth but by moral falsity [section XI(A)]. Of course, the benefits people are interested in when they act. for the reflexive goods cannot reasonably be anticipated unless the goods are morally specified and pursued accordingly. For instance, people cannot live together in peace without true justice. However, that is not self-evident nor can it be deduced from the relevant first principle of practical knowledge by itself. Thus, the first principles of practical knowledge which correspond to the reflexive goods are logically open to being specified immorally. When they are, interest in them may not have the priority which virtuous. people give their interests in the reflexive goods.

Although it is difficult to conceptualize the reflexive goods without importing real or apparent moral values, a precise articulation of these basic goods would avoid describing them in moral terms. Generally, our previous writings did not avoid that. Rather, we called the har- 
mony between judgments and choices "practical reasonableness," that between choices and performances "authenticity," that among persons "justice," that with God "holiness" or "the agreement of human free choices with God's will," and so on.

\section{Purposes in Life, Commtments, and Life Plans}

Morally good people do have definite purposes in life which extend far beyond anything they expect to realize through choices of particular actions. For example, a married couple with children have the purpose of raising their children. This purpose in obvious ways organizes a large part of their lives. And this structuring is morally required of them, not a matter about which they are free to do as they please.

Not every couple need have the purpose of raising children since not every couple has children. But for those who do, the requirements of basic goods to be realized in the children, together with the moral requirements of family solidarity, demand that the relationships of the woman and man to one another and to their children be chosen as a long-term ordering principle of their lives. This choice is a commitment. The object of the commitment includes all the benefits hoped for in raising the children. So, this purpose is a moral principle in the sense that it is a source of integration in the lives of parents.

Most people hope for benefits besides those which pertain to family life. Fulfillment in any of the basic goods can (at least under some conditions) require dependable cooperation for an indefinite period among two or more persons. The securing of such cooperation requires other commitments to act with others-for example, in work outside the family, in seeking knowledge and communicating it to others, and in maintaining social peace.

Each of the purposes in life established by a commitment organizes a significant part of a person's life. Indeed, as experience teaches, the parts of one's life organized in this way often overlap. Therefore, a good person, conscientious about fulfilling responsibilities, will try to work out a unified, rational plan of life so that anticipated benefits will be realized as fully as possible through actions which do not interfere with one another.

For such persons, living according to their plan of life and enjoying the benefits of doing so is a significant part of the happiness for which they are prepared to settle. A sign of the soundness of their attitude is that morally sensitive people regularly say of good people who have died, "So-and-so had a happy life," when they had a clear plan of life, held to it to the end, and within normal limits achieved their purposes. 
Yet a happy life in this sense does not comprise every benefit which will be sought by a good person. Play often is the sole reason for choosing a morally acceptable action. The mother who writes poetry in her free moments, the pope who occasionally skis, are engaging in humanly fulfilling activities which they need not direct to any of the purposes set by their commitments and which they can undertake without making any additional commitment of the sorts considered thus far.

For this very reason, such activity and the benefits enjoyed in it often are considered of little moral significance, and the good of play often is considered a rather odd sort of basic good. Still, without being tightly integrated under one's life plan, play-and other goods as well, at times-can significantly contribute to the happiness of a good life.

\section{Morality, Religion, and God}

\section{A. Why a Religious Commitment Is Required}

A morally good person's plan, as described thus far, will coordinate several purposes and leave room for activities done for still other benefits. But we said [section $X(C)$ ] and in this final part of the paper will try to show that the life of a virtuous person should be unified in view of a single purpose.

We think that such a purpose can be established by a religious commitment and cannot be established without it. Why do we think so?

Every human fulfillment can be considered a participation in divine goodness-goodness itself [section XI(B)]. Many morally good persons consider real this participating of their acts in the goodness of God, whom they regard as a transcendent source of meaning and value. So, such persons believe that the good of religion-that is, harmony with the source or sources of meaning and value-is morally exigent whenever it is at stake.

Clearly, this good is in fact realized whenever one must choose between what is right and what is wrong, and chooses what is right. The question, however, is: How does the good of religion come to be at stake in such a way that it becomes a distinct reason for acting? And why is a specific commitment to it morally necessary?

Contingent realities, including human persons and their lives, point to a transcendent reality: something which is, is not contingent, and is the source of everything contingent. Only such a source can account for the is of what is but need not be. Hence, there is a more-thanhuman source of the whole world, including human experience, feeling, thought, volition, action, and fulfillment. Moreover, because contingent reality is but need not be, its transcendent source is reasonably 
thought of as if it were causing through free choice. If so, it is like an acting human person, causing according to a plan, and so is the source of the meaning which human thought finds in reality.

The directiveness of practical knowledge is one contingent reality among others; like any other, it points to its transcendent source. But the directiveness of one's practical knowledge also points to a trańscendent source in another and special way. For the is-to-be of the principles of practical knowledge not only is underived but is known to be underived-that is, to be a starting point which humankind does not give itself but naturally has as a precondition for all human selfdirection and rationally guided action. Just as the is of any contingent reality as such points to its transcendent source, so the is-to-be of the directiveness of practical knowledge points to its transcendent source. But since, in this case, the transcendent source is of directiveness, that source can only be thought of as if it were a person anticipating human fulfillment and leading human persons toward it.

Aware of this more-than-human source of meaning and value, most human persons also are acutely aware that they are not in complete harmony with it. For everyone sometimes makes immoral choices. And everyone finds the natural environment, which so clearly points to its transcendent source, in some respects a hard and cruel world. The fish are not to be found; crops fail; fire destroys carefully built dwellings; everyone gets sick, is hurt, and eventually dies. Harmony with the morethan-human source of meaning and value plainly must be pursued.

But how to begin to pursue harmony with a more-than-human person is far from clear. It is not like pursuing harmony with the people next door. Thus, most men and women of most times and places have recognized that they should seek to know what they can about this transcendent source, learn how to get along with it, and put into practice what they learn. In other words, among the natural responsibilities of human persons is the duty to seek religious truth, embrace what appears to be that truth, and live according to it.

Those who sincerely try to fulfill this fundamental religious duty realize that they cannot do so as isolated individuals but only in their various communities. Different groups of people accept as true different views of God and his relationship to humankind, and so develop diverse practices in their efforts to live in harmony with God. Both because these practices aim to serve vitally important purposes and because these purposes are related to constant features of any community's life, dependable cooperation in them is morally required, and so morally good people make a communal religious commitment.

In a simple culture, people may not clearly ditsinguish this commitment from their commitment to live with one another at peace; religion 
is simply a vital and pervasive aspect of the people's whole way of life. But the religious commitment is distinguishable insofar as it structures cooperation not only among people themselves but also with God (or the gods). Prayer and sacrifice, for example, are parts of almost every people's effort to interact with the divine, using as a model the ways people living together in peace interact with one another: by conversation, sharing the necessities of life, and gift-giving.

\section{B. God: Cooperator with Human Agents}

To understand how only a religious commitment can integrate the whole of a morally good life, one must understand more exactly the inevitable and dynamic relationship between morality, immorality, and religion of various sorts. To understand this, one must consider two things: first, how the human will, although not naturally oriented toward divine goodness as its object [section $\mathrm{X}(\mathrm{B})$ ], comes to will that goodness in the course of willing human fulfillments; and second, how this concomitant willing of divine goodness develops into selfish love in morally bad wills, but would develop into genuine mutuality in a morally good will.

The truth of practical knowledge anticipates that to which it is adequate [section VI(A-B)]. In every rationally guided and freely chosen action, one not only wills some basic good, emotionally desires to bring about an expected state of affairs as the goal of one's performance, and chooses to do something, but wills (intends) anticipated benefits, in which one is interested for oneself and/or another. So, every action is done in the hope that it will contribute to fulfillment.

Just insofar as a benefit is to be realized through the action whose intelligible purpose it is, this fulfillment is not known in advance. For one cannot know just what one can be before one lives (nor, for example, what one's children can be before one has children and brings them up).

Moreover, the fulfillment one hopes for is not in one's own power. In acting, one always hopes for the best. When action is fruitful as one hopes it will be, the fruit always depends on factors in addition to one's action. Thus, success in achieving the benefits one intends is anticipated but cannot be taken for granted.

And in hoping, even if one does not think about it clearly, one hopes in whomever or whatever will make one's effort fruitful. When success comes, one can say that fate smiled and thank one's lucky stars. Or one can receive the hoped for benefit as a gift-unexpected insofar as it is surprising-and thank God for it, thinking that his providence and benevolence made fruitful the work of one's hands. 
Therefore, in intending an anticipated and hoped for benefit, every human person in every action wills, in more or less complete accord with practical knowledge, that the benefit come about both through the action and through whatever other causality is required, insofar as that fulfillment is beyond the agent's own knowledge and power.

Insofar as one hopes in persons rather than in mere things, the fruit of one's own action necessarily is seen as the fruit of the other's action as well. But, as we have explained, the transcendent source both of the is-to-be of practical knowledge and of the actuality of every hoped for fulfillment is naturally thought of as if it were a person. Therefore, for those who recognize the reality of a more-than-human personal source of meaning and value, every human action is carried out in cooperation with that unseen, more-than-human source, understood to be both directing human persons toward their fulfillment and helping them to bring it about.

In any cooperation, the other party, as a personal agent, also has intentions. Cooperation occurs because both parties hope to share in fulfillment. But common fulfillment is the set of benefits in which persons acting together are interested. So, in willing one's own fulfillment through action, one also wills what in fact will fulfill the other. Hence, in every action every human person naturally and necessarily wills (what cannot be thought of otherwise than as) a fulfillment of the unseen source of meaning and value.

(God's "fulfillment" is spoken of here and in what follows by relational predication; such predication posits in God only some perfection, in itself beyond human understanding, sufficient to sustain the relationship which some immanent reality has to him. Thus, propositions involving relational predication about God's "fulfillment" do not-though they may seem to-imply that he lacks anything. Indeed, they are not only consistent with, but are rightly understood only by bearing in mind, those propositions which exclude from God every conceivable kind of defect, lack, and imperfection.)

This willing is the fundamental human love of God, which is natural in the sense that nobody who recognizes the reality of a more-thanhuman, personal source of meaning and value ever acts without it. It might seem that this fundamental love of God necessarily makes him into a mere means of achieving human purposes. But that is not so. For a means is within one's power, while God emerges in the very exercise of human agency as one who directs human persons to act and brings about what is not within their power.

Moreover, as in other cooperative relationships, people can will what fulfills the other in this relationship not only insofar as it is necessary 
for their own fulfillment and in fact fulfills the other, but precisely insofar as it does fulfill the other. In other words, in their cooperation with God, people can will his fulfillment insofar as it fulfills him. If they do so will it, they truly love God as a person-someone distinct from themselves with whom they cooperate.

\section{Religion and the Overarching Purpose of life}

Precisely here, morally good and bad wills differ. Insofar as a morally bad will intends benefits and wills what is necessary to obtain them, it also wills what is in fact the fulfillment of others, including God, just insofar as necessary to its own fulfillment. But the morally bad will does not, in its bad willing, will what fulfills God insofar as it fulfills him. Only a good will does so.

For in fettering practical reason, the bad will ignores part of the direction it receives. In rejecting morally good alternatives, therefore, it rejects the benefits which would accrue through those actions to others, including God-benefits to which unfettered practical reasons would guide action. Yet the morally bad will still hopes to benefit from the help of others, including God. Hence, the morally bad will subordinates the fulfillment of others to the benefit it seeks for itself. Rather than a relationship of mutuality, the morally bad will establishes an exploitative relationship.

Those who relate to others in this way try to coerce them, trick them, manipulate them, bargain with them, evade their claims for mutuality, and, ultimately, get along without them. Many entire religions and some forms of every religion are marked with these signs of morally bad will.

A commitment to such a religion cannot set any single, overarching purpose for one's whole life, for the purpose of such a religious commitment is strictly subordinated to one's other purposes. And such a set of purposes cannot be unified because immorality mutilates and disintegrates one's fulfillment.

But even in such cases, people's religious commitment can unify their entire plan of life as no other commitment can. For harmony with the divine, however misconceived, will be thought to condition one's hopes of achieving every other purpose in life.

A morally good will accepts all the direction it receives from practical knowledge and its transcendent source. Not rejecting any aspect of human fulfillment, it need not subordinate to itself the interests of the other with whom it cooperates. Enjoying the benefits of cooperation, the good will also can be grateful to God and rejoice in his fulfillment. 
As in every cooperative relationship, in following God's directionthat is, unfettered practical reason-people sometimes find themselves unfulfilled: They do their best yet the anticipated benefit is not realized. In experiencing and accepting failure, morally good people submit to the intention of God, who could have granted them success, but did not, obviously for some reason of his own. In this submission, human persons will God's fulfillment insofar as it fulfills him-love him as a person.

For morally good persons, their religious commitment will provide at least one purpose to integrate all their other commitments. This is so because, as we explained above [section XII(A)], the good of religion is in fact realized whenever one must choose between what is right and wrong, and chooses what is right. And so, for one striving to live in harmony with the source of the moral ought and realizing that this harmony conditions all other hopes, this good's being at stake in every area of life sets one overarching purpose: always to avoid immorality as contrary to God's intention-that is, as sin-in order to avoid disharmony with this more-than-human source of meaning and value.

Therefore, a good person whose religious view includes nothing incompatible with moral truth will settle only for a happiness which consists in living according to a plan of life unified by the purpose of avoiding sin. Although this single, overarching purpose sets no specific affirmative requirement beyond that of moral truth itself, it does integrate the whole of life, because the religious good for the sake of which morally good persons intend this purpose becomes one reason why they do everything else they do.

\section{Christian Faith: "Seek First the Kingdom . . ."}

Some religious views specify commitments of faith with far richer purposes than the negative one of remaining blameless before God. Those who share the commitment of Christian faith and those who understand its moral significance, even if they do not share it, will easily see what such a positive purpose might be and how it could integrate the whole of people's lives.

For Christian faith teaches that a divine person, the Word, became a man, Jesus, and that Jesus set about to establish a universal community, the new covenant. In this community, all men and women can cooperate with God in completing his work of creating, redeeming, and sanctifying humankind. The purpose of this cooperation is the kingdom of heaven; life on this earth is no mere means to the kingdom but its embryonic stage. As Christian faith anticipates it, the kingdom will include every sort of benefit intended by morally good wills. 
If one considers this teaching credible, one plainly ought to accept it, for it offers the hope of realizing the closest imaginable approximation to integral human fulfillment.

If one makes the commitment of Christian faith, one enters into human cooperation with Jesus: "Abide in me, and I in you. As the branch cannot bear fruit by itself, unless it abides in the vine, neither can you, unless you abide in me" ( $\mathrm{Jn} \mathrm{15:4).} \mathrm{In} \mathrm{bearing} \mathrm{such} \mathrm{fruit,}$ one comes to love God in a new way. For, in willing one's own fulfillment in communion with Jesus, one wills the fulfillment of the divine person of the Word, according to his human nature. Jesus offers himself for those who cooperate with him: "Greater love has no man than this, that a man lay down his life for his friends. You are my friends if you do what I command you"' (Jn 15:13-14). And precisely through this offering, Jesus attains his own fulfillment: He "for the joy that was set before him endured the cross ..." (Heb 12:2).

Still, even this human love of God through human communion with Jesus in itself anticipates only human fulfillment: the overcoming of sin and death. However, Christian faith also teaches that as the Word became a man without ceasing to be God, so human persons without ceasing to be human can become sharers in the divine nature-can receive a second birth by water and the Spirit or a second nature by divine adoption. Sharing in the divine nature, human hearts are filled by the Spirit with divine love, so that they can enter into a communion whose purpose is fulfillment in divine goodness: "The glory which thou hast given me I have given to them, that they may be one even as we are one, $I$ in them and thou in me, that they may become perfectly one ..." (Jn 17:22-23).

Insofar as it is lived for the sake of the kingdom, Christian life has but one purpose. The happiness for which those who live such a life are prepared to settle embraces every human fulfillment for which they hope. Moreover, mediated by their human solidarity with Jesus but beyond the limits of merely human peace with God, they hope for intimate communion in divine joy. This gift they anticipate not insofar as they remain human but insofar as they also are somehow divine: "Beloved, we are God's children now; it does not yet appear what we shall be, but we know that when he appears we shall be like him, for we shall see him as he is" (1 Jn 3:2).

\section{A Second Thought}

Whenever one makes any choice, one's will, insofar as it is a rational appetite, must be specified by some intelligible good. Whenever one makes a morally good choice and in many cases when one makes a morally bad choice, that specifying good either is or is reducible to 
the instantiation of one or more of the basic human goods. Until after we completed the manuscript of this article, we assumed that what is true in many cases is true in all cases [see especially sections VII(A). and $\operatorname{VII}(C)]$.

However, as this article is about to appear, we are having a second thought on this point. It may be that the intelligibility which specifies the will in making certain immoral choices merely is to use effective means to satisfy desires, hostile feelings, or other emotions, whose precise objects are not reducible to any of the basic human goods. If so, the basic human goods are not reasons for such immoral choices, but only serve to rationalize them.

Even if some immoral choices can be made without in any way having their reason in any of the basic human goods, we do not think the account of practical truth and moral truth we offer here would require very much revision.

\section{SElECted BibliographY}

Please note: This list includes only some of the authors' works in ethical theory; it omits other works, mainly concerned with aspects of their theory which are not treated in this article. The notations are intended primarily as guidance for those who wish to examine the theory critically.

Germain Grisez. "Man, Natural End of." New Catholic Encyclopedia (1967) 9:132-38. This article points out inconsistencies in Thomas Aquinas's teaching on the natural end of human persons, examines the efforts of various Thomists to make sense of that teaching, and stops just short of rejecting key aspects of it (and similar views of Aristotle and Augustine). None of Grisez's pre-1964 publications should be considered sources for the theory, which was first articulated in this and the next two items, written (in the order listed here) during 1963-64. Of works listed here, this and the next are Grisez's only attempts at Thomistic exegesis. Elsewhere, he tries to do philosophy or theology, not history, and freely parts company with Thomas, usually without saying so.

"The First Principle of Practical Reason: A Commentary on the Summa Theologiae, 1-2, Question 94, Article 2." Natural Law Forum 10 (1965): 168-201. (Abridged version in Modern Studies in Philosophy: Aquinas: A Collection of Critical Essays, ed. by Anthony Kenny, 340-82. Garden City, N.Y.: Doubleday, 1969. Because Kenny did some significant, unauthorized editing, this version should not be used by critics.) Insofar as this article goes beyond exegesis and begins articulating a free-standing theory, its treatment is superseded by recent works, not least the present article.

. Contraception and the Natural Law. Milwaukee: Bruce, 1964. Chapter three is an early version of the theory; for understanding its mature form, only the critique of "conventional" natural-law approaches remains helpful, and that is supplemented in later works. The critique of consequentialism ("situationism") here, and up to "Choice and Consequen- 
tialism," mistakenly focuses on the noncommensurability of the categories of basic goods.

"Methods of Ethical Inquiry." Proceedings of the American Catholic Philosophical Association 41 (1967): 160-68. (Reprinted in New Dynamics in Ethical Thinking, ed. by George F. McLean, O.M.I., 99-107. Lancaster, Pa.: Concorde, 1974.) The statement of the theory here is superseded by later works. The brief critique of alternative theories also is superseded by later and more adequate exercises in dialectic, especially that in Finnis's Fundamentals of Ethics.

. Abortion: The Myths, the Realities, and the Arguments. New York and Cleveland: Corpus Books, 1970. Chapter six is a restatement of the theory, with its application to abortion and other killing, including capital punishment and war. This statement of the theory is superseded by later works, including the present article. (However, the treatment of the issue of the personhood of the unborn and most of the factual content of this book remain useful.) Some find this statement of the theory attractive, perhaps partly because later and more adequate versions are more complicated. Germain Grisez and Russell Shaw. Beyond the New Morality: The Responsibilities of Freedom. Notre Dame and London: University of Notre Dame Press, 1974; 2nd ed. rev., 1980; 3rd ed. rev., 1988. Intended for use with beginning students as part of an introduction to ethics, this is a simplified articulation of the theory by Shaw, a professional writer. Many important aspects of the theory and arguments for it are deliberately omitted, even from the newest edition. Those who wish to interpret and criticize Grisez's thought are warned in the introduction that he "has set forth his ethical theory at length and in the language of technical philosophy in other publications."

Joseph M. Boyle, Jr. "Aquinas and Prescriptive Ethics." Proceedings of the American Catholic Philosophical Association 49 (1975): 82-95. By clarifying the difference between Hare's prescriptivism and the theory's account of is-to-be and ought, this article shows that an evaluative conception of good need not entail noncognitivism:

Germain Grisez. Beyond the New Theism: A Philosophy of Religion. Notre Dame and London: University of Notre Dame Press, 1975. The metaphysical foundations of the ethical theory are explained and defended in this book, which had the benefit of many years of work with Boyle and Tollefsen, especially on the book listed next. The argument from the directiveness of practical reason for the existence of God is not developed in this book, and the implications of practical knowledge for knowledge of God are only hinted at (84-91). But relational predication concerning God is treated fully (256-72).

Joseph M. Boyle, Jr., Germain Grisez, and Olaf Tollefsen. Free Choice: $A$ Self-Referential Argument. Notre Dame and London: University of Notre Dame Press, 1976. The most complete account of free choice and related elements of action theory, and a criticism of alternative views of these matters, which are so basic for sound ethical theory.

Germain Grisez. "Choice and Consequentialism." Proceedings of the American Catholic Philosophical Association 51 (1977): 144-52. The first presentation of the mature version (which corrects earlier ones) of the argument 
against consequentialism based on the noncommensurability of those anticipated benefits and harms which are the intelligible grounds for the options, one of which is freely chosen. This critique is superseded by the article listed next.

"Against Consequentialism." American Journal of Jurisprudence 23 (1978): 21-72. The most extensive critique of consequentialism, but completed in some respects by later treatments.

Germain Grisez and Joseph M. Boyle, Jr. Life and Death with Liberty and Justice: A Contribution to the Euthanasia Debate. Notre Dame and London: University of Notre Dame Press, 1979. Chapters eleven and twelve are still useful for their articulation of some aspects of action theory not treated in the present paper, and for application of the theory to life and death issues. Grisez and Boyle now recognize that the political and legal philosophy in this book needs some corrections. These made, their views in these areas would be closer to the positions developed by Finnis in the book listed next, yet some differences might remain.

John Finnis. Natural Law and Natural Rights. Oxford and New York: Oxford University Press, 1980. Chapters III-V deploy the ethical theory; chapter XI.8 gives an account of the relation between reason and will in choice; chapter XIII considers the divine cause and end of human existence. To understand this book aright, one should note that whenever Thomas Aquinas is quoted or cited, the author is to be taken (except in a few cases where he expresses a reservation) to mean to adopt Aquinas' view. The treatment of incommensurability fails to distinguish the two theses distinguished in the present paper. Partly because of considerations of audience and partly because the author did not then see the matter clearly, his exposition here of the ethical theory did not identify the role of integral human fulfillment.

' Natural Law and the 'Is' - 'Ought' Question: An Invitation to Professor Veatch." Catholic Lawyer 26 (1981): 266-77. A defense of the theory's conception of practical knowledge against serious misreadings both of Natural Law and Natural Rights and (it is argued) of Thomas Aquinas.

John Finnis and German Grisez. "The Basic Principles of Natural Law: A Reply to Ralph McInerny." American Journal of Jurisprudence 26 (1981): 21-31. A defense against misunderstandings of the theory and (it is argued) of Thomas Aquinas; the authors point out, however, that the theory's adequacy is not its correspondence with the views of any previous thinker.

John Finnis. Fundamentals of Ethics. Oxford: Oxford University Press; Washington, D.C.: Georgetown University Press, 1983. A restatement of much of the theory by way of a dialectic with Aristotle, Kant, and contemporary English-language work in ethical theory.

Germain Grisez, with the help of Joseph M. Boyle, Jr., Basil Cole, O.P., John M. Finnis, John A. Geinzer, Jeannette Grisez, Robert G. Kennedy, Patrick Lee, William E. May, and Russell Shaw. The Way of the Lord Jesus, vol. one, Christian Moral Principles. Chicago: Franciscan Herald Press, 1983. (Boyle contributed more than six months of full-time work to this volume.) Chapters two through twelve offer the most mature statement of the theory as a whole. Chapters nineteen and thirty-four give a theological account of the ultimate end of human persons. The rethink- 
ing of the theory in a theological context and without reference to any particular issue (such as abortion or euthanasia) led to many important developments, and a considerable increase in the clarity and precision of the theory as a whole. Still, some aspects of this treatment are filled out in more recent works, including the present article, which also corrects some details.

John Finnis. "Practical Reasoning, Human Goods, and the End of Man." Proceedings of the American Catholic Philosophical Association 58, forthcoming. slightly revised: New Blackfriars 66 (1985): 438-51. A comparison of the ideal of integral human fulfillment with the ultimate end as Aquinas understands it. Finnis, whose view is closer than Grisez's to that of Aquinas, here emphasizes points of agreement.

Joseph M. Boyle, Jr. "Moral Reasoning and Moral Judgment." Proceedings of the American Catholic Philosophical Association 58 (1984): 37-49. An account of the extent to which nonrational factors necessarily and rightly enter into moral reasoning and moral judgment, and so require virtue for the perfect attainment of moral truth.

" "Aquinas, Kant, and Donagan on Moral Principles." New Scholasticism 58 (1984): 391-408. An examination of various formulations of the first principle of morality, and criticism of the "respect persons" formulation, favored by Donagan over the theory in its previous formulations.

John Finnis, Joseph M. Boyle, Jr., and Germain Grisez. Nuclear Deterrence, Morality and Realism. Oxford and New York: Oxford University Press, 1987. A fresh, philosophical presentation of the theory, with a careful application to the morality of nuclear deterrence.

Germain Grisez. "The Structures of Practical Reason: Some Comments and Clarifications." Thomist 52, forthcoming. A reply to Brian V. Johnstone, C.Ss.R., defending the theory's conception of practical principles against the alternative views of them (which Johnstone tries to combine) as theoretical truths or as imperatives. The constructive presentation of the theory here is superseded by that in the present article.

"Natural Law and Natural Inclinations: Some Comments and Clarifications." New Scholasticism 61 (1987): 307-20. A reply to Douglas Flippen, both defending the theory against misunderstandings and criticizing misinterpretations of Aquinas. Here, too, the constructive presentation of the theory is superseded by that in the present article. 
